\title{
La ocupación PARACAS EN El Sitio El Mono, valle de Chincha, Perú
}

\author{
Elizabeth Isla Cuadrado ${ }^{\text {a }}$
}

\begin{abstract}
Resumen
En el valle de Chincha se han identificado, hasta hoy, numerosos sitios y asentamientos arqueológicos de filiación Paracas. Entre estos destacan grandes complejos arquitectónicos que conservan edificaciones con arquitectura de tipo monumental, asi como también varios edificios menores de carácter público, notándose al mismo tiempo pocos sitios de vivienda. Uno de estos sitios con edificios menores corresponde al sitio arqueológico El Mono, el cual está ubicado en la margen izquierda del valle medio-alto de Chincha y cerca del actual poblado de El Carmen. En el lugar se encuentran varios montículos bajos de planta rectangular que en su interior esconden pequeños edificios hechos con muros de adobes y piedras. Este es uno de los primeros sitios de la época Paracas en donde se realizaron excavaciones cientificas en los años 1985 y 1987. En dos de los montículos presentes en el sitio las excavaciones han puesto al descubierto pequeñas estructuras arquitectónicas conformadas por plataformas bajas y escalonadas pertenecientes a la época Paracas Tardio. En los rellenos constructivos se encontraron diversos materiales culturales, en especial fragmentos de cerámica del estilo Pinta según la secuencia propuesta para el valle de Chincha, la cual es comparable con la fase Ocucaje 8 (300 a.C.) del valle de Ica. En este artículo se presentan las evidencias registradas en 1987 durante las excavaciones en uno de los edificios (Edificio C1) del sitio El Mono, que en 1992 constituyó el tema de mi tesis para obtener la Maestría (Diploma de DEA) en "Historia del Arte y de la Arqueologia Precolombina», Universidad de Paris I-Sorbona, Francia. En base a ellas, se discutivá la función que tuvieron estos pequeños edificios, resaltando sus implicancias en el desarrollo de la cultura Paracas Tardío en el valle de Chincha.
\end{abstract}

Palabras clave: valle de Chincha, cultura Paracas, sitio El Mono, Pinta, Ocucaje, excavaciones.

\section{Abstract}

\section{THE PARACAS OCCUPATION AT EL MONO SITE, CHINCHA VALLEY, PERU}

In the Chincha valley, numerous archeological sites and settlements of Paracas affliation have been identified to date. These include large architectural complexes that preserve monumental architecture, several smaller buildings with public architecture, as well as very few housing sites. One of these sites with smaller buildings corresponds to the archaeological site El Mono, which is located on the left bank of the middle-high valley of Chincha, and near the present town of El Carmen. In this site there are several low mounds of rectangular shape that inside hide small buildings made with adobe and stones walls. This is one of the first sites of the Paracas period in which scientific excavations were carried out in 1985 and 1987. Recent excavations made in two of the mounds have exposed small architectural buildings made up of low and staggered platforms belonging to the Late Paracas period. In the construction fillings were found different cultural remains, especially sherds of the Pinta style following the sequence of the Chincha valley, which is comparable with the Ocucaje 8 phase (300 b.C.) of the Ica valley. This article presents the evidence recorded in 1987 during excavations in one of the buildings (Building C1) of El Mono site, which in 1992 was the subject of my thesis for obtaining the Master's Degree (DEA diploma) in "History of the Art and the Pre-Columbian Archaeology", University of Paris I Sorbona, France. Based on them, the role of these small buildings will be discussed, highlighting their implications in the development of the Late Paracas culture in the Chincha valley.

Keywords: Valley of Chincha, Paracas culture, El Mono site, Pinta, Ocucaje, excavations.

a Investigadora asociada al Instituto de Estudios Arqueológicos (INDEA)

Correo electrónico: flordeilo@wanadoo.fr 


\section{Introducción}

El Mono, como sitio arqueológico, toma su nombre de uno de los dos canales que pasan cerca a los lados norte y oeste ${ }^{1}$ de este sitio. Fue identificado por primera vez por Dwight T. Wallace durante los trabajos de prospección que realizó en el valle de Chincha en 1957-58 y registrado como sitio PV 57-63. El sitio es descrito como una ligera elevación y varias depresiones localizadas en el borde de la pampa de Carmen Alto, en cuya superficie había piedras, adobes semicilíndricos y fragmentos de huesos, por lo que Wallace pensó que se tratarían de tumbas. También menciona un muro de tapia que pasaba cerca (Wallace 1971).

En 1984-1985, en el marco de los trabajos realizados en este valle por el Proyecto Arqueológico Histórico Chincha-Pisco (PAHChP), Lumbreras describe el sitio como un conjunto arqueológico conformado por seis a siete montículos separados en tres sectores: A, B y C. El sector A, compuesto por dos montículos y dos estructuras de tapia, una rectangular y la otra cuadrangular de período más reciente. El sector B por un montículo aislado y el sector C por dos montículos (Lumbreras 1985: 2). Este último sector no fue identificado por Wallace. Según Lumbreras, los edificios identificados podrían ser parte de un mismo complejo y de una misma época asociada con la cultura Paracas.

En 1985, sobre la base del reconocimiento de superficie realizado por el PAHChP, se planificó el examen del proceso de evolución que tuvieron las ocupaciones en el valle de Chincha, partiendo desde el Horizonte Temprano. Hasta entonces, este período era reconocido como el más antiguo en el valle y, según la secuencia establecida por Wallace (1972), la fase Pozuelos marca el inicio de ese período. En las investigaciones del PAHChP no se hallaron materiales de esta fase, por lo que el estudio de los asentamientos empezó con la siguiente fase conocida como Pinta (Lumbreras 1987). Esta fase fue aislada por Wallace en el sitio PV57-59 y toma su nombre de la Hacienda Pinta, que se encuentra en la proximidad. Wallace pensaba que allí habría un probable cementerio (Wallace 1970a: 15), mientras Lumbreras describe ciertas depresiones rectangulares que habrían servido como tumbas. El sitio es conocido hoy como Cerro del Gentil.

En este contexto, en 1985 se iniciaron las excavaciones en el sitio El Mono, específicamente en el sector B. Se prefirió excavar con prioridad en este sitio debido a que estaba en un proceso de deterioro muy avanzado. Cabe mencionar que han sido numerosos los sitios con rasgos de la fase Pinta identificados por el proyecto en el valle medio-alto y valle bajo de Chincha. Más tarde, en 1987, siguiendo el programa de investigaciones del PAHChP, las excavaciones continuaron en el sector $\mathrm{B}$ del sitio, pero al mismo tiempo se abrieron nuevas unidades de excavación en los sectores A y $\mathrm{C}$.

Las excavaciones a mi cargo en el sector $\mathrm{C}$-montículo $\mathrm{C} 1$ - han permitido identificar una serie de estructuras arquitectónicas que, según los rasgos y materiales asociados, parecen haber tenido un solo tiempo de ocupación relacionada con la fase Pinta, según la secuencia del valle de Chincha (Wallace 1972: 1), comparable con la fase Ocucaje 8 (Menzel et al. 1964). Así mismo, las evidencias indican que los edificios habrían cumplido funciones distintas a la doméstica, tal vez como espacios de carácter ritual o ceremonial en donde se depositaban ofrendas de productos cultivados en el valle y de recursos marinos.

\section{Contexto geográfico y cultural}

El sitio arqueológico El Mono se localiza en la margen izquierda del valle de Chincha, en la costa centro sur del Perú, a 200 kilómetros de Lima (Fig. 1). El valle de Chincha a su vez constituye el límite entre dos grandes zonas geográficas que, a lo largo del tiempo, han marcado los procesos sociales en el área andina: el norte fértil y el sur árido (Lumbreras 1981).

En este contexto, el valle de Chincha ocupa la parte norte de la región Ica, adyacente al Océano Pacífico (Fig. 2). Tiene una superficie de forma casi triangular, surcada por una red hidrográfica conformada por el río San Juan y sus tributarios, que forman la principal fuente de agua del valle. 


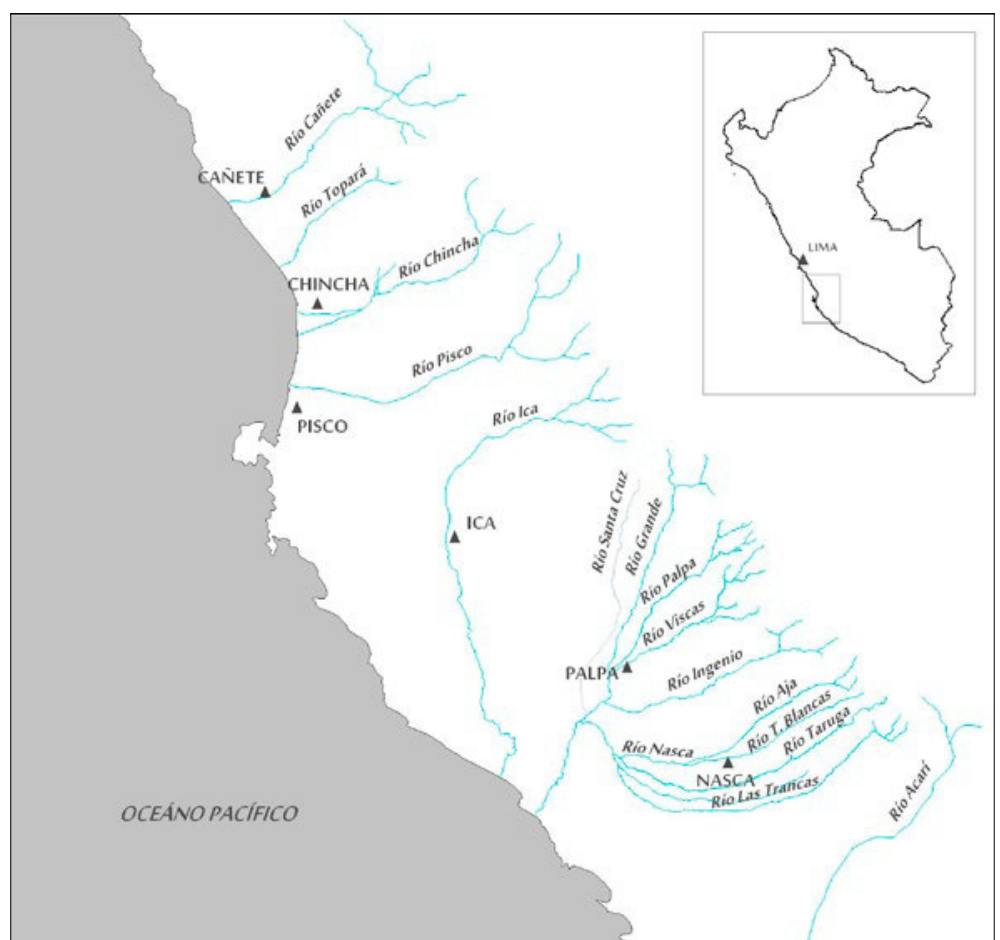

Figura 1. Mapa de la costa sur del Perú con ubicación del valle de Chincha y otros valles mencionados en el texto, donde se ocurrió la influencia de la cultura Paracas.

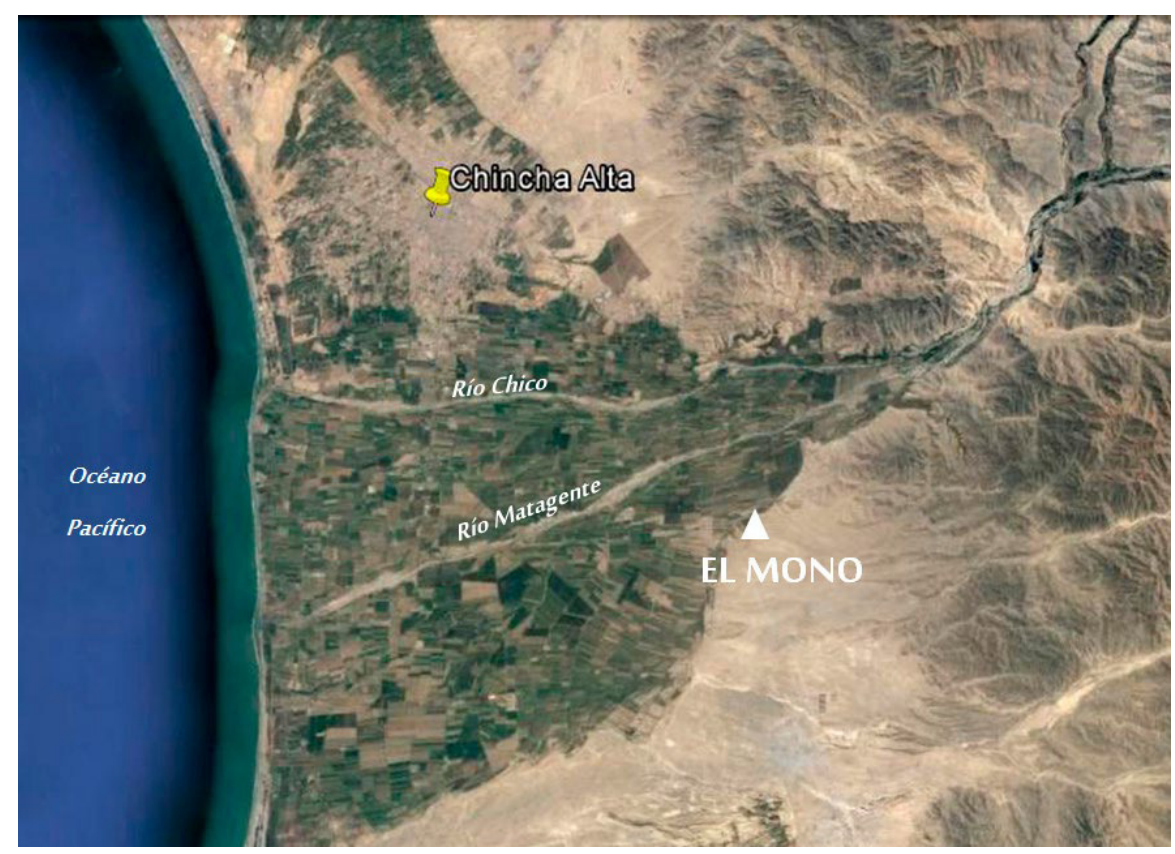

Figura 2. Foto satelital del valle de Chincha con ubicación del sitio arqueológico El Mono en el contexto del valle (fuente: Google Earth). 
El río San Juan tiene su naciente en la vertiente occidental de la Cordillera de los Andes y desciende hacia el mar en dirección oeste. A la altura del pueblo de Conta, a 20 kilómetros del océano Pacífico, el río se divide en dos ramales formando el río Chico hacia el Norte y el río Matagente hacia el Sur, desde donde se considera la parte baja del valle. En la parte baja el valle tiene más de 15 kilómetros de Norte a Sur, mientras que al Este está flanqueados por las primeras estribaciones de la cordillera andina.

El valle de Chincha tiene un clima templado, con $19.5^{\circ} \mathrm{C}$ promedio (con una máxima de $30{ }^{\circ} \mathrm{C}$ en verano y una mínima de $11^{\circ} \mathrm{C}$ en invierno), siendo uno de los valles más ricos y fértiles de la región, con suelos casi planos de tipo aluvial que ocupan más de 30 mil hectáreas, que en su mayoría se destinan a la agricultura (ONERN 1970: 48). A principios del siglo pasado, Uhle lo describía como «uno de los más bellos y ricos valles de la costa peruana» (Kroeber y Strong 1924: 60). Los terrenos fértiles han permitido desarrollar, a lo largo del tiempo, una actividad agrícola intensa sobre la cual se sustenta la economía de sus ocupantes. Esto se complementaba con los recursos del mar, formando una sólida base económica que desde tiempos prehispánicos constituye uno de los principales medios de subsistencia de la población.

Arqueológicamente, el valle de Chincha se encuentra integrado a un largo proceso cultural que se encuentra más relacionado con la costa sur, integrada por los valles de Chincha, Pisco, Ica, Palpa, Nasca y Acarí, en donde se desarrollaron varios grupos culturales (Menzel 1959; Massey 1986, 1990), entre los que destacan tres de las más importantes formaciones sociales del área andina: Paracas, Nasca y Chincha. Cabe indicar que las poblaciones de la costa sur, desde el Formativo, se distinguieron de aquellas de la costa central y norte por sus diferentes «estilos cerámicos, organización socioeconómica, política e ideológica, así como en los patrones de interacción inter e intrarregional» (Silverman 2009: 431; ver también Kroeber 1944, 1953; Strong 1957; Rowe 1960). En este contexto, durante el Horizonte Temprano y el Período Intermedio Temprano, en el valle de Chincha se llegaron a distinguir tres culturas o estilos bien definidos: Paracas, Topará y Carmen (ver Wallace 1986; Peters 1997). El sitio de El Mono o Chococota se relaciona con la cultura Paracas (800-200 a.C. $)^{2}$.

\section{Las investigaciones sobre la cultura Paracas en el valle de Chincha}

Las primeras informaciones sobre la ocupación Paracas en Chincha se remontan a 1901, cuando Max Uhle realizó sus primeras investigaciones en el valle (Uhle 1924). Aunque nunca se publicaron sus trabajos en detalle, se sabe que Uhle visitó el sitio La Cumbe en donde, entre otros materiales, destaca el hallazgo de un fragmento típico de los "platos ralladores» Paracas (Kroeber y Strong 1924: fig. 12b), al cual relaciona con las fases más tardías de Paracas. Lo mismo sucedió en la Huaca Alvarado, a la cual se refiere simplemente como «una vieja huaca» (ibid. 51-52). Más tarde, Kroeber y Strong, después de un análisis de los trabajos de Uhle, notan que la Huaca Alvarado estaba construida con adobes esféricos o «terrones», diferentes de otros sitios de Chincha, que ellos la relacionan con una cultura más reciente que llamaron «Proto Chincha» (op. cit.: 52-54; lámina 9 y 20).

Después de los trabajos de Uhle hubo un gran vacío en los estudios arqueológicos hasta los años 1957-58, cuando Wallace realizó trabajos de prospección en los valles de Cañete, Chincha y Pisco. En el curso de estos trabajos, Wallace llegó a registrar más de 100 sitios arqueológicos en Chincha, que cubrían todos los períodos de tiempo, desde el Horizonte Temprano hasta los inicios del período Colonial. En este mismo tiempo, Wallace realiza dos excavaciones ${ }^{3}$ (Wallace 1959, 1970 a, b; Wallace 1971). Sus investigaciones formaban parte de los trabajos que la Fundación Fullbright auspiciaba en el Perú durante los años cincuenta, cuyo objetivo principal era el estudio de materiales y contextos arqueológicos que permitan establecer secuencias de cronología arqueológica, en los valles de la costa sur. 
En este sentido, Wallace focaliza sus estudios entre el Horizonte Temprano y el Intermedio Temprano. Según Dorothy Menzel (1971: 97-98), la información sobre estos períodos era inexistente en ese tiempo. Los estudios de Wallace coinciden con los trabajos que al mismo tiempo realizaban Fréderic Engel $(1963,1966)$ en la costa central y Lawrence Dawson en los valles más al sur. En todo caso, resultaba urgente establecer una secuencia cronológica en estos valles para poder relacionarlo con los materiales descubiertos por Julio C. Tello en las necrópolis de la península de Paracas.

Estos trabajos permitieron a Wallace establecer la primera secuencia cultural del valle que sintetiza la historia arqueológica de Chincha para estos períodos (Wallace 1959). Esta secuencia fue elaborada a partir de dos pozos de sondeo (de 2 metros por 2 metros) y que se basa principalmente, en la interpretación de la variación de los estilos. Conviene señalar igualmente, que se trata del único estudio que pone en relación los estilos de cerámica de cada fase con los esquemas de evolución de los asentamientos. Según Wallace, la aparición de conjuntos arquitectónicos de tipo ceremonial (montículo-templo) en el valle, están relacionados con la tradición Topará, mientras que pocos montículos-templos están asociados a las últimas fases de la cultura Paracas y en las que el adobe en forma de "grano de maíz» fue utilizado preferentemente en sus construcciones (Wallace 1959; 1970 a, b; 1972; 1986). En este sentido y considerando el estado de las investigaciones de la época, los trabajos de Wallace han contribuido notablemente al conocimiento arqueológico del valle de Chincha y también de gran parte del departamento de Ica.

En el año de 1983, se retomaron las investigaciones en el valle de Chincha con la puesta en marcha del PAHChP. Estos trabajos pusieron en evidencia la existencia de una importante ocupación prehispánica en este valle, con una concentración de sitios Paracas - especialmente de edificios monumentales - en la parte baja del valle (Fig. 3). Si bien en la introducción ya hice referencia a los trabajos realizados en el marco de dicho proyecto, en este punto conviene agregar que en dichos estudios no solo se logró identificar numerosos nuevos sitios, sino que también se constató que algunos sitios reconocidos por Wallace habían desaparecido por causa de las actividades agrícolas. En este sentido, el informe preliminar de dicho proyecto proporciona elementos interesantes para el estudio de las ocupaciones y el patrón de asentamiento en el valle (Lumbreras 1987).

Cabe indicar, que si bien los resultados de las investigaciones realizadas en el marco del PAHChP todavía no han sido publicados en detalle, algunos avances importantes, además del presente trabajo, han sido hechos por José Canziani con respecto a la arquitectura paracas, quién sostiene que el éxito político y económico alcanzado por los paracas en el valle de Chincha —al menos en la época tardía-, se debió a la existencia de un eficiente sistema de irrigación relacionado con los edificios de adobe localizados en la parte baja del valle (Canziani 1992,1994, 2009; Canziani y Del Águila 1994).

\section{La cronología Paracas en Chincha}

Las investigaciones iniciales sobre la cultura Paracas en el valle de Chincha han permitido identificar básicamente tres fases o estilos alfareros: Pozuelos, Pinta y San Pablo, las cuales cronológicamente se suceden una a la otra. Estas fases, a su vez, son claramente comparables con las fases definidas por Dawson en el valle de Ica (Rowe 1958).

La fase Pozuelos fue reconocida por Wallace y Lanning en los niveles inferiores de un pozo de prueba — de 2 metros por 2 metros - excavado en el sitio de Pozuelos (PV 57-52) y que para ellos marcaba el inicio del Horizonte Temprano en el valle. El sitio se encuentra a 1.5 kilómetros de distancia del mar, al norte de la Hacienda San Pablo y está conformado por una serie de montículos de poca altura (Wallace 1971: 42). Durante la prospección en el valle, Lumbreras ha constatado que Pozuelos es el único sitio representativo de esta fase. La poca cerámica asociada, es bruñida con decoración tipo «impreso" (dentate rocker stamping and rouleting) y que Wallace pone en relación con el estilo Curayacu 3 de la Costa central. Durante estos trabajos Lumbreras (comunicación 


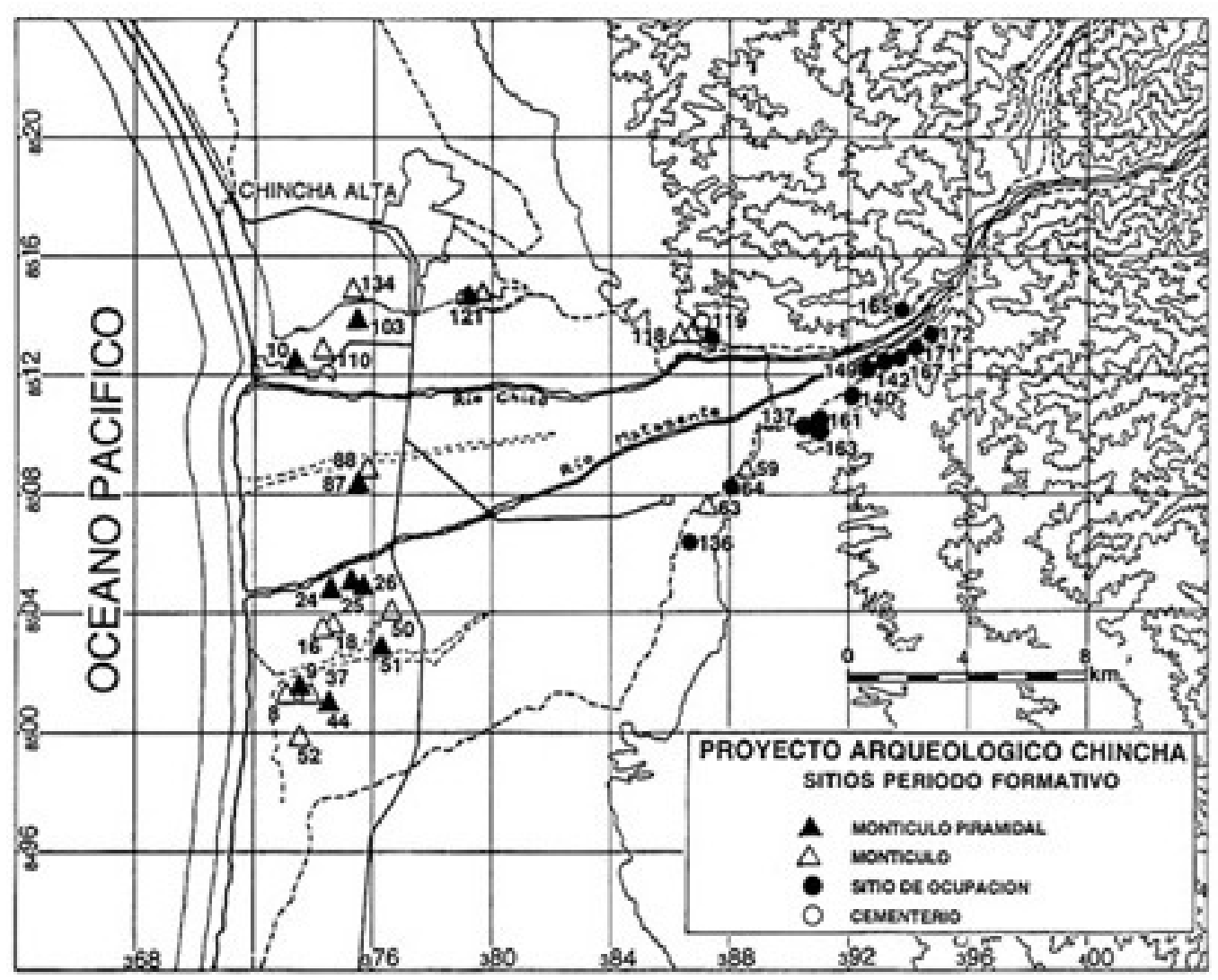

Figura 3. Mapa del valle de Chincha con ubicación de los principales sitios arqueológicos del Periodo Formativo registrados durante los trabajos del Proyecto Arqueológico Chincha (fuente: Canziani 2009: fig. 168).

personal) indicó haber identificado un tipo de cerámica distinta, aparentemente igual o más antigua que la cerámica Pozuelos. Constatar esta hipótesis permitiría extender la secuencia temporal de la cultura Paracas en el valle de Chincha.

Por otro lado, la cerámica del estilo Pinta fue aislada en el sitio PV 57-59, en donde según Wallace (1972: 1) «presenta fragmentos que no están mezclados y en número suficiente para indicar una fase local, llamada Pinta, ... distinta de la de Ica, a pesar que sus semejanzas sugieren su contemporaneidad con la fase Ocucaje 7». Más tarde, Wallace define esta cerámica como de excelente calidad y sugiere que en esa época las influencias se desarrollaron de Chincha hacia el valle de Ica y de Chincha hacia el área de Paracas (Wallace 1985: 73-74). La hipótesis de Lumbreras es que en la fase Pinta del desarrollo Paracas, se observan las «primeras evidencias de establecimientos con edificios no domésticos... y que comienza un proceso de organización social de base urbana, con una organización racionalizada de la producción agrícola, marítima y urbana...» (Lumbreras 1987a: 2-3, 8-9). Durante los trabajos de prospección se registraron diversos sitios relacionados con esta fase (Fig. 3), en los cuales la mayor parte del material de construcción está compuesto por adobes en forma de "grano de maíz» y de piedras.

En cuanto al valle de Pisco, Engel (1957) identificó el estilo alfarero Tambo Colorado cuyas características, en general, son semejantes a las del estilo Pinta de Chincha. Para Lanning, la diferencia significativa entre estos dos estilos, reside en la utilización de resina de color amarillo usado como fondo decorativo en la cerámica Pinta y que es reemplazada, en ciertos casos, por un baño de pintura color rojo en la cerámica Tambo Colorado (Menzel 1971: 107). 
Finalmente, después de la fase Pinta se reconoce el estilo San Pablo, el cual fue descubierto en superposición al estilo Pozuelos en el sitio PV 57-52. Según Wallace (1972: 1), se trata de un tipo de «cerámica monocroma, con decoración incisa y negativo - Menzel resalta la ausencia total de pintura poscocción a base de resinas - cuyas características indican una fusión completa de la tradición local Paracas con influencias del norte, de la tradición Topará, y que debe ser contemporánea con la fase Ocucaje 9 de Ica». Por su lado, Lumbreras considera este estilo como parte del estilo Topará. El estilo San Pablo ha sido identificado en numerosos sitios del valle Chincha y en algunos otros del valle de Cañete, siendo reemplazado por la tradición Topará que marcó la etapa de transición del Horizonte Temprano hacia el Intermedio Temprano.

La Tradición Topara está dividida en tres fases: Jahuay 1, 2, 3 (fase más antigua, descubierta por Lanning en 1956), Chongos y Campana. En sus trabajos más recientes, Wallace (1986) hizo una clasificación más detallada de la cerámica de esta tradición, donde incluyó la cerámica hallada en el sitio La Quebrada del valle de Cañete (Wallace 1963), logrando así otras subdivisiones de la fase Jahuay 2, Chongos y Quebrada. Aunque la cerámica de este estilo no es el tema de este artículo, brevemente se debe anotar que, según Wallace, el estilo Topará está en directa relación con las fases finales del estilo Ocucaje, con influencia muy marcada durante las fases 9, 10 y Nasca 1. Indica también que Topará está asociado a la presencia de grandes templos —9 en Chincha y 2 en Pisco- que, debido a su situación en la parte baja del valle, con ausencia de sitios de habitación e instalaciones parecidas, pueden ser calificados como centros ceremoniales (Wallace 1971: 1-2, 1986: 42-45). Por su parte Lumbreras sostiene que en ese tiempo hubo un notable crecimiento poblacional y que su densidad habría generado la aparición de zonas altamente productivas en la parte baja del valle. Datos más detallados sobre los estilos del Horizonte Temprano se encuentran en los estudios de Lanning (1960) y Menzel (1971).

\section{Ubicación y descripción del sitio}

El sitio arqueológico El Mono (PV 57-63) se localiza en la margen izquierda del valle de Chincha, exactamente en el extremo noroeste de las pampas conocidas como Carmen Alto u Hoja Redonda, justo arriba del borde del valle. Esta zona forma parte del distrito de El Carmen Alto (Fig. 4). En ese lugar se encuentran varios montículos bajos y alargados que en general tienen una orientación esteoeste, los cuales en realidad constituyen pequeñas estructuras arquitectónicas hechas con muros de adobes y piedras.

Según sus rasgos morfológicos, el sitio fue dividido en tres sectores: A, B y C (Fig. 5). La distancia entre los sectores A y C es de 480 metros. Todas las estructuras se encuentran bastante erosionadas porque se han convertido en una zona de paso entre las pampas de Carmen Alto y la zona agrícola adyacente, por donde pasan manadas de cabras que han causado un serio deterioro al sitio. Las estructuras del sector $\mathrm{C}$ ocasionalmente también han sido utilizadas como corrales abiertos para esa clase de ganado.

El Sector A ocupa el lado Oeste del sitio está compuesto de cuatro subsectores que han sido designados como A1, A2, A3 y A4. El subsector A1 comprende un montículo de planta rectangular de unos 30 por 40 metros de lado, con 3 a 4 metros de altura, se orienta en sentido EsteOeste. En la parte superior se observan dos pozos huaqueados en donde se pueden ver los restos de lo que parecen ser tumbas de forma rectangular con paredes revestidas de piedra. El subsector A2 comprende otro montículo situado al Este de A1, el cual se encuentra muy deteriorado y por tanto no se pudo evaluar ni su forma ni sus dimensiones, aunque se estima que pudo ser similar al montículo A1, con unos 2 metros de altura y también una orientación este-oeste. El subsector A3 se localiza al Sur de A2 y fue parcialmente excavado en 1987. Allí se puso al descubierto un espacio aparentemente rectangular (su lado Oeste no fue identificado). Tiene 30 por 60 metros de lado, delimitado con muros de piedra de doble cara y con divisiones al interior. Su eje más largo 


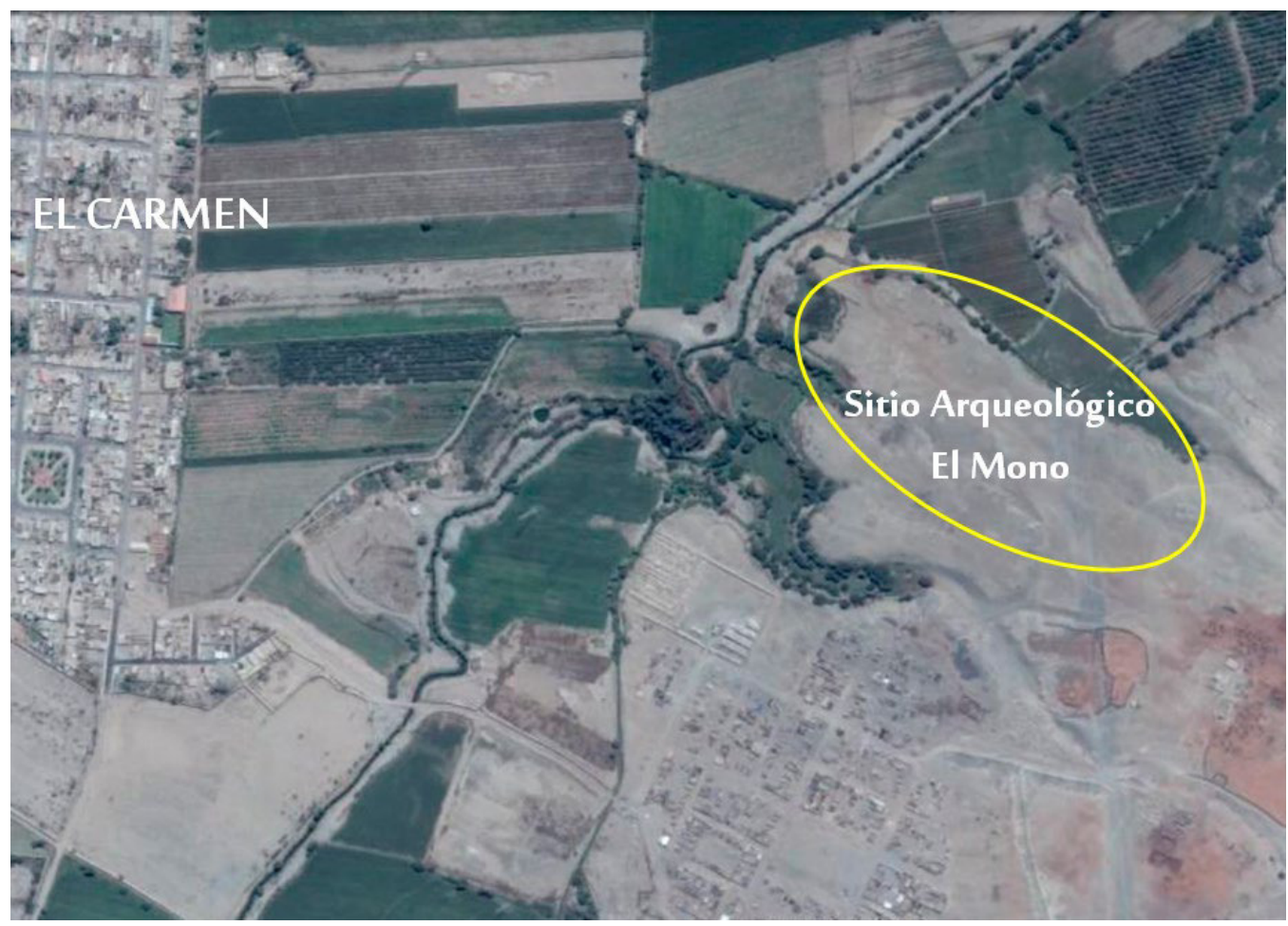

Figura 4. Foto aérea con ubicación del sitio arqueológico El Mono en relación con el valle y el poblado de El Carmen (fuente Google Earth).

está orientado de norte a sur. Los resultados preliminares de las excavaciones, indican que se trata de una estructura arquitectónica de filiación Topará, y según las apariencias «...sería una zona de habitación ligada a funciones domésticas...con al menos un sector destinado al trabajo de fibras.» (Juan C. Tello 1987: 23). Finalmente, el subsector A4 situado al Este de A3, es una estructura de forma "cuadrangular», hecha con muros de adobe y cuyo lado Este no existe. Según Lumbreras, este edificio correspondería a una época diferente de los otros tres, donde la forma, la técnica de construcción y la cerámica asociada son de factura más reciente.

El Sector B se localiza a 60 metros al Este del sector A y fue parcialmente excavado en 1985 y 1987. Se trata de un montículo aislado de planta cuadrangular que tiene unos 30 metros de lado y 2 metros de altura. Los muros que componen el edificio estaban hechos en base a piedras de campo, unidas con mortero de barro y paja, aunque algunos muros estaban hechos con pequeños adobes en forma ovoide hechos a mano («adobitos»). Después de la primera temporada de excavaciones, se llegó a plantear que el edificio fue «... en su origen, un recinto destinado al almacenamiento de alimentos y de vegetales... asociado a una ocupación durante la fase Pinta y después reutilizado... en los inicios de la fase Topará» (Lumbreras 1987a: 7). Todo esto fue confirmado por las excavaciones de 1987.

Finalmente, el Sector C se localiza a 160 metros al Este del sector B y está conformado por tres montículos denominados C1, C2 y C3. Tienen formas y dimensiones variadas y están alineados en dirección noroeste-sureste. El montículo $\mathrm{C} 1$ es el más grande y aparentemente el mejor conservado del sector C, el mismo que fue objeto de nuestras excavaciones en 1987. El montículo tiene una forma casi rectangular de 22 por 36 metros de lado y 3 metros de altura, con su eje más largo orientado en sentido Este-Oeste. Su lado norte se encuentra muy cerca del borde del terraplén que delimita la pampa de Carmen Alto y el valle, la cual se encuentra a unos 10 metros de altura con respecto al piso del valle (Fig. 6). 


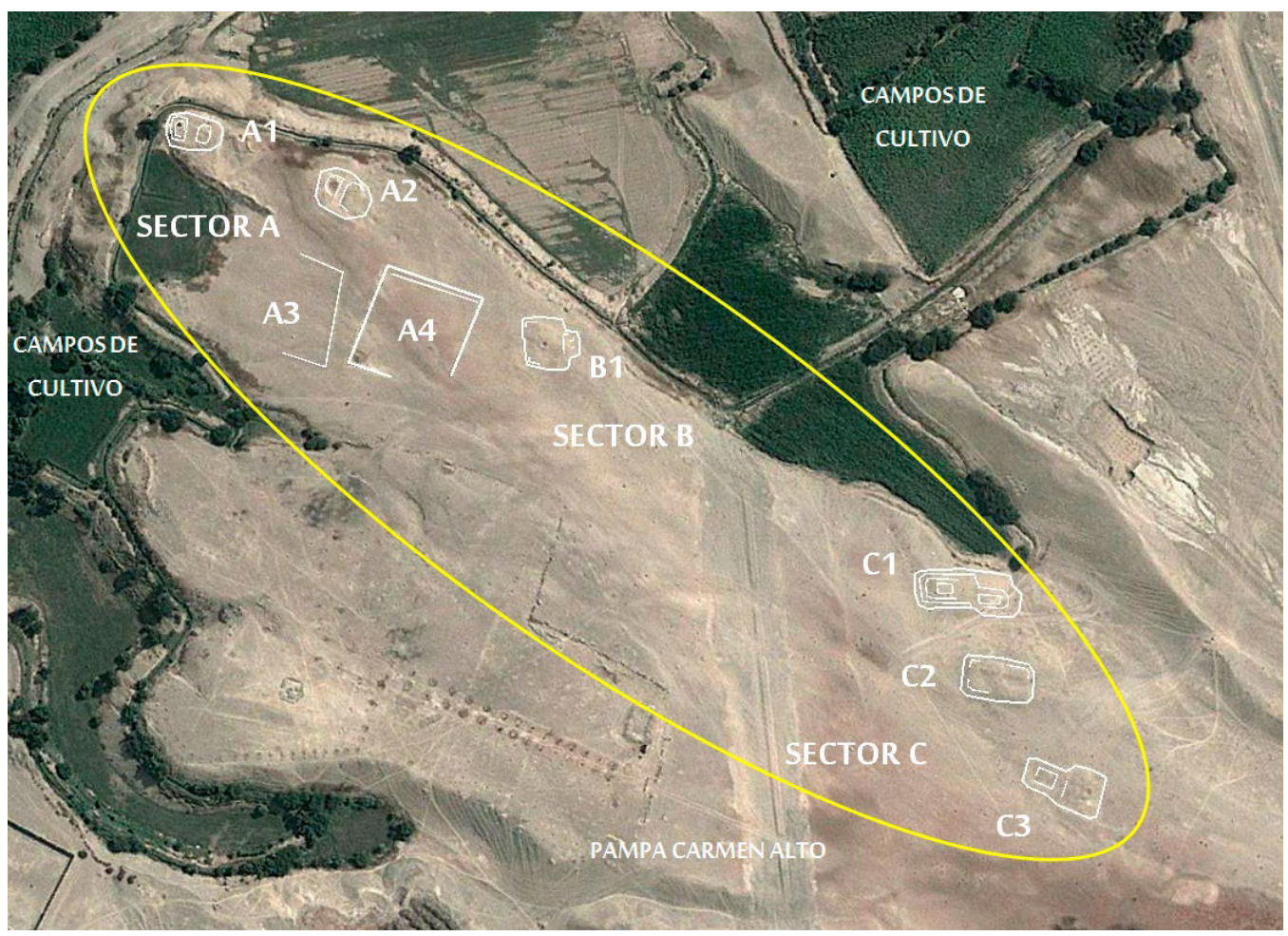

Figura 5. Plano esquemático del sitio arqueológico El Mono con ubicación de los sectores $(A, B$ y $C)$ en los que fue dividido. Básicamente se trata de montículos bajos de planta rectangular (Foto Google Earh 2010).

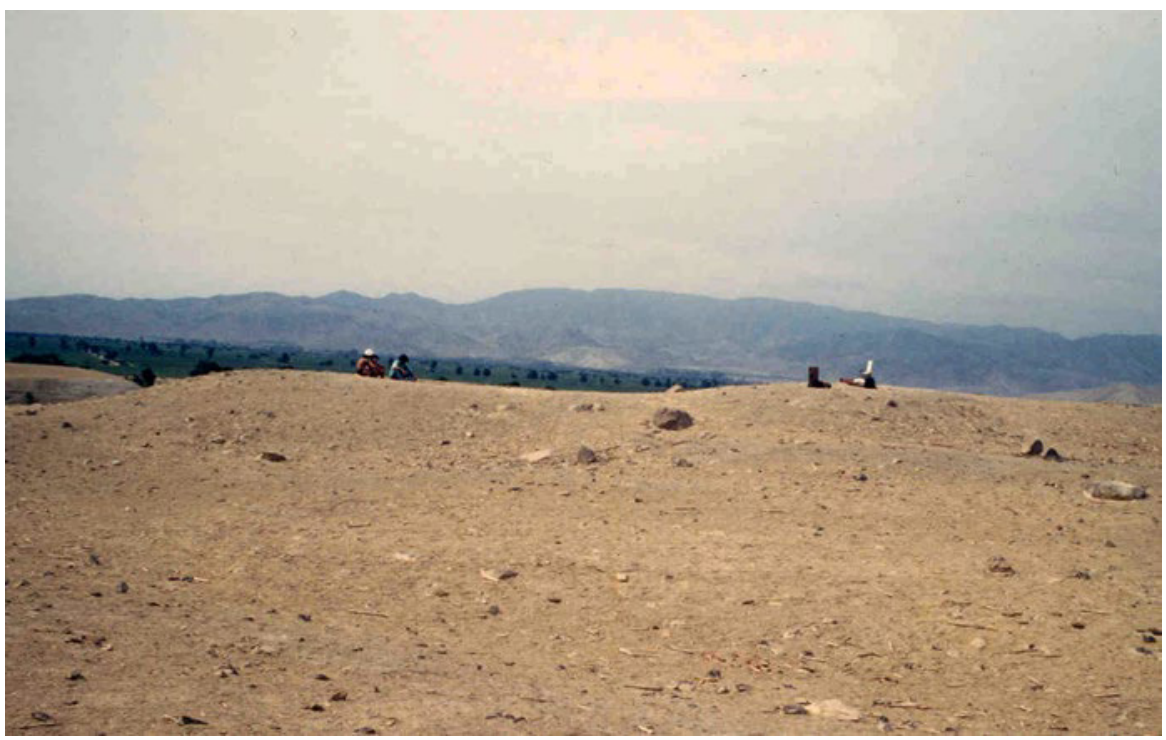

Figura 6. Vista panorámica del montículo que comprende el sector C1. 
Después de las excavaciones y de manera preliminar, el montículo (que fue dividido en dos secciones: Este y Oeste), puede ser definido como una estructura con secciones arquitectónicas diferentes. En la mitad Oeste del montículo, hay una plataforma (plataforma occidental) rectangular de 14 por 16 metros de lado y 1.5 metros de altura, la cual presenta en su parte central un patio hundido de forma rectangular que mide 4 por 6 metros de lado y entre 0.5 y 0.8 metros de profundidad. El piso, que reposa directamente sobre el terreno natural, no es plano debido a la irregularidad de la pampa. La existencia de dos muros de contención interiores adosados a sus lados Norte y Sur define una forma romboidal. En el lado exterior norte de la plataforma hay dos muros de contención muros N9 y N11, este último está asociado a un piso ligeramente inclinado que se extiende por unos 4 metros hacia el borde de la pampa.

La mitad este del montículo se divide en tres secciones: una sección Sur, en la cual se encuentra una plataforma rectangular (plataforma sureste) con alrededor de 6 por 17 metros de lado y 1.5 metros de altura. Se piensa que sus extremos están conformados por terrazas escalonadas, pero no hubo tiempo de verificarlo. Una sección central (antigua terraza Este) comprende un patio de forma rectangular con aproximadamente 4 por 13 metros de lado, está delimitado al Norte por un murete (N3), al Sur por la plataforma sureste, al Oeste por la plataforma occidental; su lado Este no fue excavado, es de baja altura y también puede estar delimitado por un murete. Una sección Norte comprende una terraza (terraza posterior) de 4 metros de largo, fue establecida sobre un piso inclinado (corredor Oeste) adyacente al murete N3. Esta terraza (terraza posterior) está delimitada en su extremo norte por un muro de contención (muro N8) asociado a un piso que se extiende por 1,5 metros. hasta el borde de la pendiente de la pampa.

Finalmente, los montículos C2 y C3 se localizan al sureste del montículo C1 y son los más pequeños del sitio El Mono, con menos de 1 metro de altura. El montículo C2 tiene además un contorno irregular y en la parte superior presenta una depresión circular que podría ser producto de un huaqueo. Por su lado el montículo C3 tiene forma alargada y en algunas partes de su contorno sobresalen restos de muros que parecen corresponder a una plataforma, cuyo acceso estaría en el lado Sur.

\section{Las excavaciones en el edificio $\mathrm{C} 1$}

Las excavaciones en el edificio C1, se realizaron principalmente con el objetivo de realizar un examen de sus componentes morfoestructurales y establecer su situación cronológica en relación con el sitio mismo y el valle. Hipotéticamente, lo habíamos asociado a las otras construcciones del sitio (A1, A2 y B) debido a las características similares de la arquitectura y la cerámica de prospección, lo cual sugería que pertenecía a la misma época, aunque no necesariamente habrían coexistido.

Los muros de piedra visibles en su parte superior, muy parecidos a los del edificio B, parecían establecer una relación directa entre ellos. Una hipótesis inicial suponía que el edificio B era un templo pequeño (Lumbreras 1985: 48), pero las excavaciones de 1987 parecen más bien sugerir que éste habría sido destinado al almacenamiento de alimentos. En este sentido, las excavaciones en este edificio fueron necesarias para conocer su función y sus probables relaciones.

Como he seńalado anteriormente, el montículo $\mathrm{C} 1$ presentaba elementos diagnósticos - muros parcialmente visibles en la plataforma occidental y oriental — que permitían una mejor evaluación de sus componentes. Una vez identificados estos elementos físicos, hemos realizado excavaciones estratigráficas en área en base a unidades que van desde 1 a 4 metros cuadrados (Fig. 7). La descripción del proceso de excavación que sigue a continuación se hace en forma resumida siguiendo el método ampliamente desarrollado por Lumbreras (1985: 12-14). 


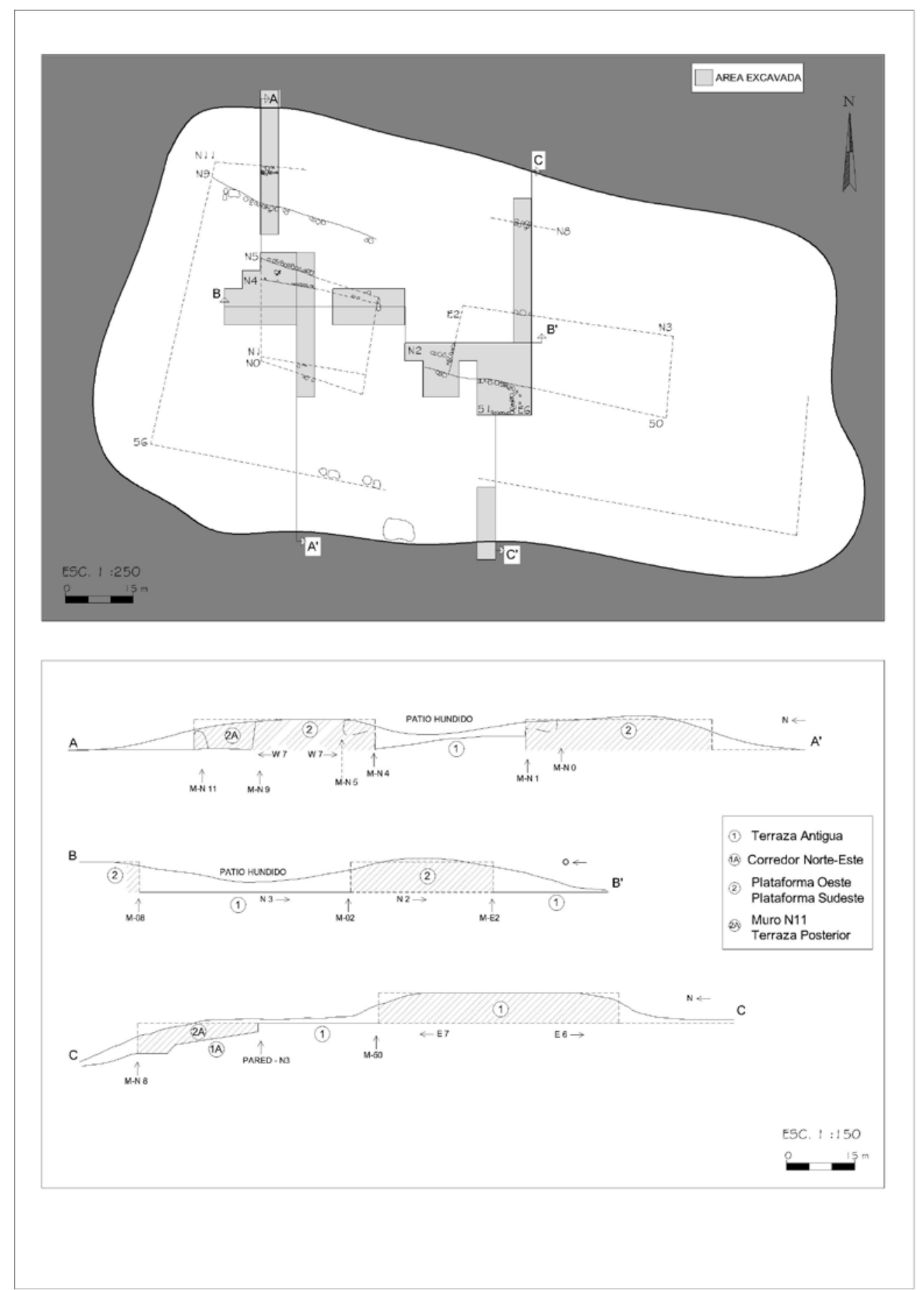

Figura 7. Plano esquemático del montículo C1 ubicado en el sector $C$, con detalles de planta y perfiles del mismo, así como también de las áreas excavadas en 1987. 


\subsection{Descripción de la estratigrafía}

El montículo estaba completamente cubierto por una tierra fina y polvorienta de color beige (capa S), la cual era el producto de la erosión humana y de una fuerte erosión eólica que soporta la zona. Se registraron también grandes piedras dispersas, concentración de hojas y tallos de maíz, estiércol de animales que es el resultado de la utilización reciente del sitio como corrales para ganado caprino que ocupan las zonas circundantes.

Luego de retirar la capa superficial, se registró una capa A que indica un contexto de abandono de la estructura, de un espesor variable entre 20 y 30 centímetros. Estaba compuesta mayormente por tierra y grava. Se registraron solo unos pocos fragmentos de cerámica, restos de vegetales, moluscos e hilos de colores.

Seguidamente hallamos una capa de escombros correspondiente al derrumbe de los muros y de los materiales de relleno de las plataformas o de la terraza (capa B). Se presenta en forma de talud, donde la parte más gruesa está apoyada a los muros y se extiende en función de la cantidad de los escombros —entre 1.6 y 1.8 metros—, su espesor fue de 30 a 40 centímetros en la parte más gruesa y de 3 a 5 centímetros en su parte más delgada. Al pie de la plataforma Este alcanza un espesor mayor a 80 centímetros. En la mayor parte del edificio la capa estaba depositada directamente sobre el piso, con excepción del patio hundido, en donde estaba cubriendo otras capas. Esta capa estaba compuesta por piedras grandes — que provienen de los muros-y piedras pequeñas — de 2 a 10 centímetros- mezcladas con tierra, terrones y regular cantidad de fragmentos de cerámica, valvas de moluscos, restos vegetales, etc. Conviene indicar que en las zonas donde los muros son de poca altura, los derrumbes son formados generalmente por material de relleno y algunas piedras grandes.

Luego de retirar los escombros se expuso una capa principal (capa C) y otras tres pequeñas capas $(\mathrm{B} 2, \mathrm{D}, \mathrm{E})$, todas en estrecha relación y que nos proporcionaron información significativa sobre la construcción y función del edificio. La capa $\mathrm{C}$ ha sido encontrada únicamente delante del lado Norte del patio hundido (muro N4), desde donde se extiende hasta 1,2 metros de distancia con un espesor de 10 a 20 centímetros en su parte más gruesa y 2 a 5 centímetros en su extremo más delgado. Se trata de un solo contexto que se encuentra entre las capas B y D. En su parte noroeste presenta una pequeña ramificación debido a la intrusión de la capa B2. Es una deposición muy homogénea, poco compacta y que presenta un gran núcleo de combustión que corresponde a un fogón ${ }^{4}$, el cual se compone de ceniza mezclada con poca cantidad de tierra y piedras pequeñas, fragmentos de carbón y de cerámica que están mayormente quemados, así como de restos vegetales variados y valvas de moluscos.

El fogón, es de forma irregular y tiene 80 centímetros de diámetro aproximado. Está compuesto de una gran concentración de ceniza y en su núcleo se hallaron fragmentos de terrones quemados y rojizos, que suponemos habrían servido de soporte de objetos de cerámica. En el interior del fogón se registró igualmente una notable concentración de fragmentos de cerámica, algunos con decoración incisa, bases, bordes de ollas y otros con una gruesa capa de materia orgánica adosada a su pared interior, que pueden ser restos de alimentos. Los fragmentos en su mayoría están quemados y pertenecen al estilo Pinta.

Por otro lado, las capas B2, D y E, como se dijo antes, están estrechamente relacionadas con el fogón o capa C. La Capa B2 es contemporánea a la capa C y sirvió como «soporte» del fogón por su lado Oeste, desde donde se alimentaba el fuego. Se extiende desde la esquina noreste del patio sobre un área de 1 metro cuadrado y se encuentra entre las capas B y D. Corresponde a una deposición bastante horizontal compuesta por tierra y algunas piedras, con un espesor promedio de 20 centímetros en donde se encontraron unos pocos fragmentos de cerámica y restos vegetales.

La capa D fue hallada exclusivamente en el patio hundido, depositada directamente sobre el piso de dicha estructura. Se trata de una deposición relativamente homogénea y poco compacta que estaba compuesta por arena fina (seleccionada) y algunas pocas piedras. Tenía entre 4 y 10 centímetros de espesor delante de los muros y apenas entre 1 y 2 centímetros en el resto del patio. Tenía pocos materiales culturales asociados y al parecer también fue depositada como soporte del fogón. 
Finalmente, la capa E corresponde a un pequeño depósito localizado en la esquina noreste del patio, donde se extiende por espacio de 1 metro. Se encuentra entre las capas B y D, compuesta por tierra fina y algunas piedras pequeñas, es poco compacta y tiene un espesor de 6 centímetros al pie de los muros y de 2 centímetros en sus extremos. Se encontró un fragmento de cerámica, así como hojas y tallos. También está relacionada al fogón (capa C) y presenta algunas zonas muy compactas que nos indica que por ese lado se accedía al fogón.

Por último, debajo de las estructuras excavadas se encuentra la capa natural compuesta por una mezcla de piedras, grava y arena. De acuerdo con los materiales asociados, principalmente los fragmentos de cerámica, la estratigrafía registrada indica que todas las estructuras del edificio $\mathrm{C} 1$ fueron construidas durante la fase Pinta, casi al final del desarrollo de la cultura Paracas.

\section{La arquitectura}

\subsection{Las etapas de construcción}

El análisis de la estratigrafía y de los restos arquitectónicos descubiertos durante las excavaciones en el montículo C1 de El Mono, nos ha permitido saber que las construcciones corresponden a un solo momento de ocupación, pero con dos etapas constructivas separadas por un lapso de tiempo bastante corto (Isla 1992: 44, fig. 8).

La primera etapa corresponde a la preparación del terreno sobre el cual se establecieron las construcciones. Esta etapa empezó con la nivelación del terreno para formar la estructura que llamamos terraza antigua sobre la cual se dispuso un piso bastante compacto y casi horizontal. Dicho piso estaba conformado por yeso y tierra rojiza compactada de 1 centímetro de espesor. Inmediatamente en relación con el piso (etapa 1A), se estableció un corredor en el lado noroeste, el cual a su vez tenía un piso inclinado compactado, a modo de rampa, de tierra de color marrón claro y bastante limpio, en donde no se notaba un uso prolongado.

La segunda etapa corresponde a la construcción de las plataformas (Fig. 8) y del patio hundido (Fig. 9), mientras que después (etapa 2A) se construyó el segundo muro de la plataforma occidental (muro N11) y la terraza posterior. Esto último se sustenta en la existencia de dos tipos de relleno (capa A' y B') que no se encuentra en las plataformas, en donde todas las excavaciones practicadas revelan la presencia de un solo relleno (capa B1). Esta etapa $2 \mathrm{~A}$ constituye una remodelación parcial de las estructuras, notándose en la terraza posterior el establecimiento de un muro (muro N8) que fue construido sobre una especie de murete que delimitaba el corredor noroeste. Por último, se debe indicar que el muro N11 se hizo siguiendo el mismo sistema constructivo del patio hundido, es decir, con muros asimétricos de doble contención.

\subsection{Las técnicas de construcción}

Las estructuras arquitectónicas excavadas en el edificio $\mathrm{C} 1$, al igual que las de sector B del sitio (Lumbreras 1985: 50), son relativamente sencillas y no tienen un acabado muy elaborado, siendo por lo general de dimensiones y volúmenes modestos, aunque claramente diferentes a un tipo doméstico. Formal y estructuralmente sus rasgos corresponden a recintos que tuvieron funciones distintas del nivel doméstico o de simples viviendas.

Los muros fueron construidos en base a piedras de campo unidas con mortero de barro, paja y totora (Typha sp.), las cuales fueron puestas en desorden unas sobre otras, aunque en los paramentos de los muros se observa un mayor cuidado ya que las piedras fueron colocadas con sus lados más planos hacia afuera. En la plataforma sudeste se descubrió un muro de contención interior en el cual, además del barro, se utilizó como mortero hojas de achira (Canna edulis) en gran cantidad, a tal punto que las piedras estaban envueltas por las hojas de dicha planta. Esta técnica de amarre también ha sido observada en las estructuras arquitectónicas del montículo B. 


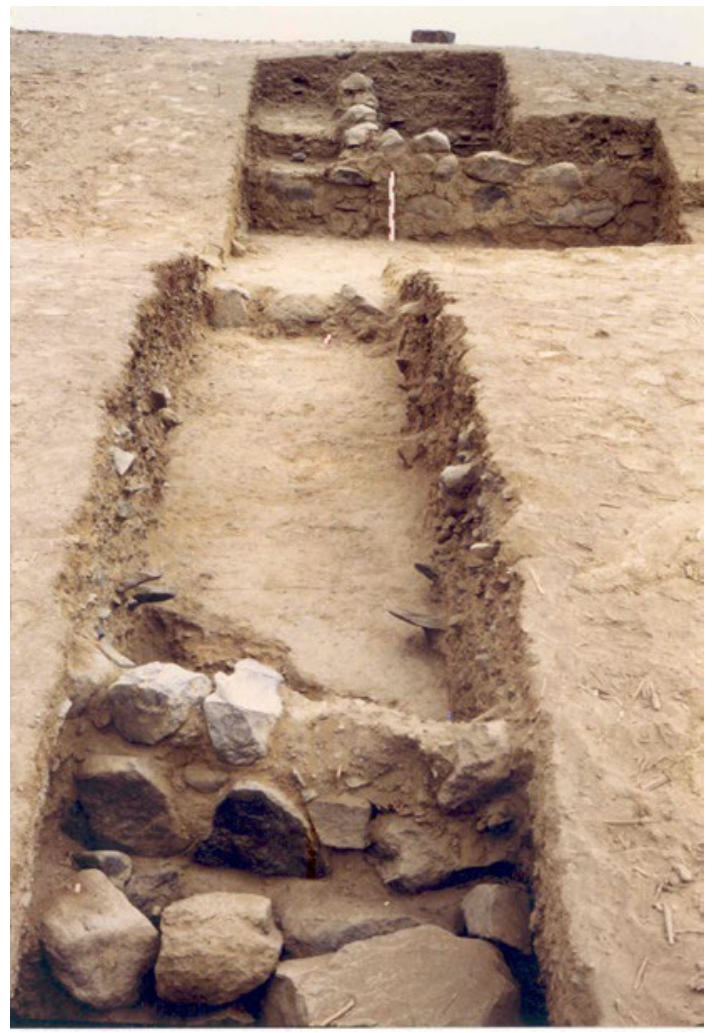

Figura 8. Vista del lado norte de la plataforma sudeste, antigua terraza sudeste, corredor sudeste. Nótese el acabado y tamaño de los muros.

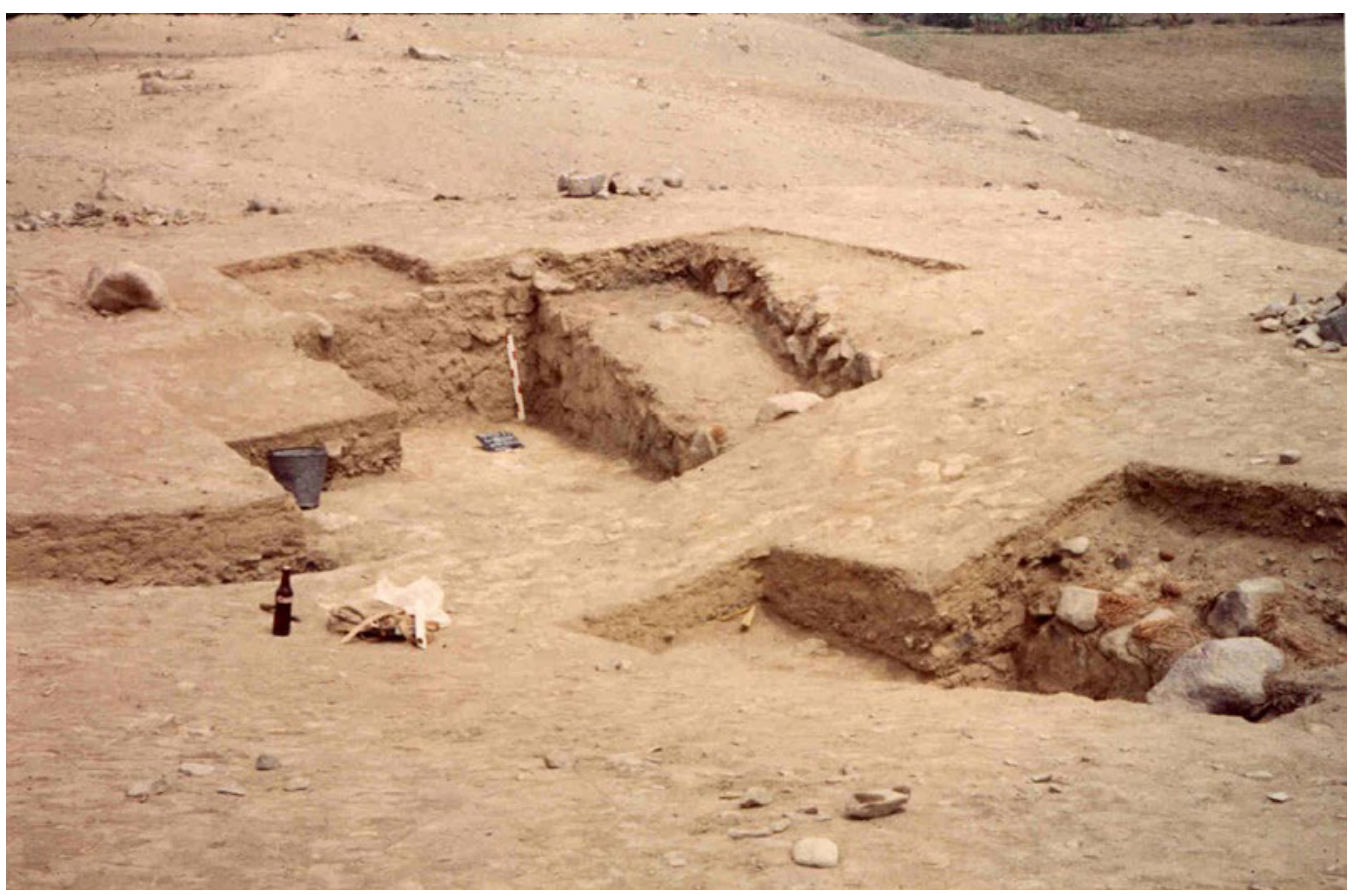

Figura 9. Vista general de las excavaciones en el patio hundido, donde destaca el piso inclinado a modo de rampa. 


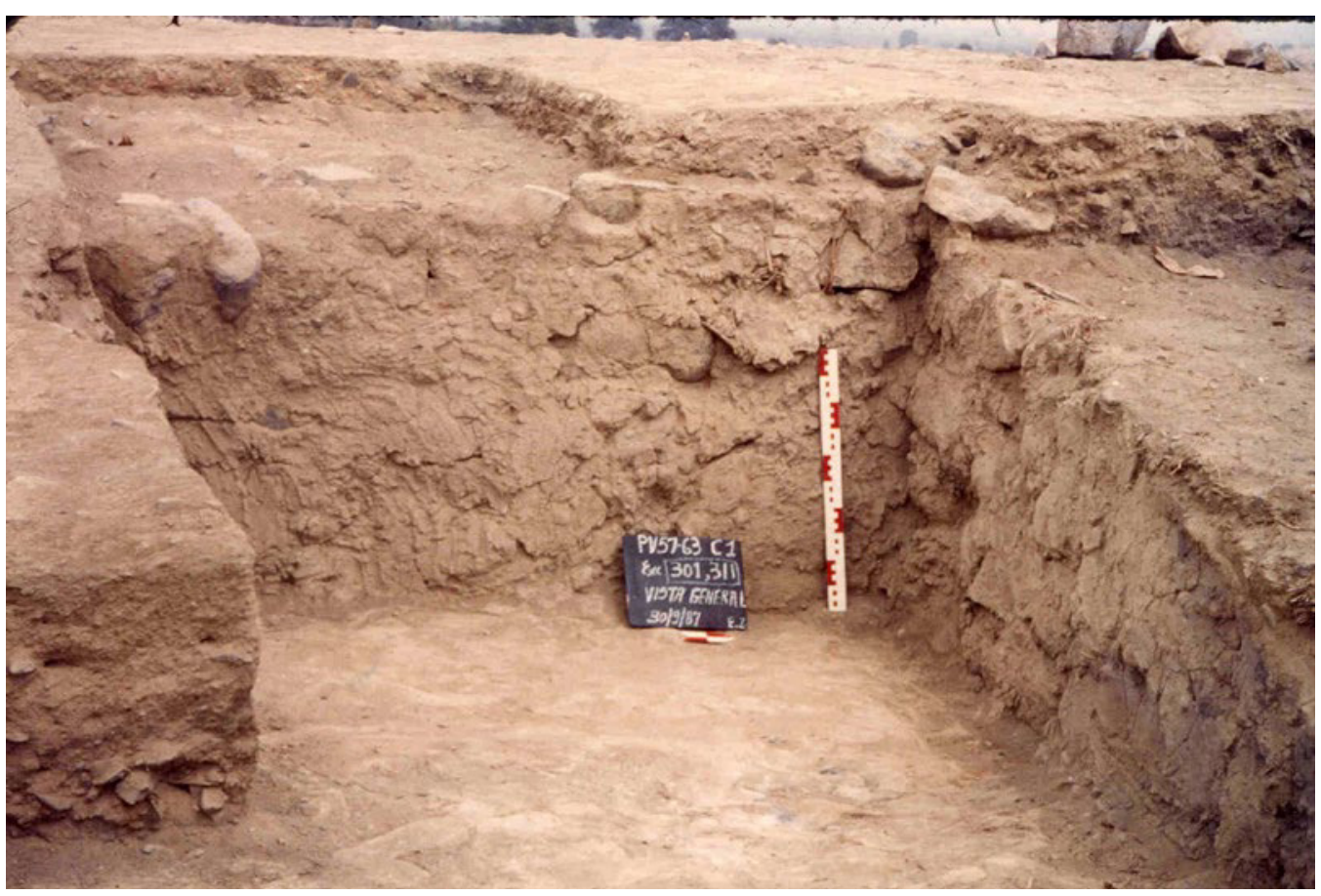

Figura 10. Primer plano de los muros en el patio hundido, en donde se puede observar la calidad del revoque y los acabados.

En general, todos los muros (a excepción del muro N8) tienen un revoque grueso formado por una capa de barro de espesor variable de entre 1 y 3 centímetros, el cual no tiene ningún acabado y por lo tanto presenta superficies irregulares. Los revoques mejor conservados se encuentran en los muros del patio, en sus lados Este y Norte (Fig. 10), mientras que en otras estructuras están muy degradados al punto que en ciertos sectores solo quedan restos de este (Fig. 8). Los muros muestran trazos rectos pero irregulares que en ciertas partes presentan ondulaciones debido a la irregularidad de sus componentes internos. Por otro lado, al interior de los rellenos se construyeron pequeños muretes hechos con piedras medianas y sin mortero, los cuales sirvieron como muros de contención.

Por último, el piso de la terraza antigua es relativamente plano y en todas las zonas excavadas, con excepción del patio hundido y del lugar en donde estaban depositadas las ofrendas, se encontraba limpio, es decir, libre de deshechos y sin evidencias que indiquen un uso constante o prolongado. Lo mismo se puede decir del piso en el patio hundido. En este sitio no se han registrado otros elementos arquitectónicos como accesos, escalinatas, etc.

\subsection{La utilización del espacio}

Aunque no se ha llegado a determinar con certeza cuál fue la función de las estructuras del montículo $\mathrm{C} 1$, las evidencias documentadas indican que no se trata de estructuras de habitación o vivienda y que, más bien, habrían tenido una función ceremonial. Los rasgos formales y constructivos, el «buen» acabado de los muros y la presencia de pisos limpios sugieren que en el sitio se realizaban actividades diferentes a las domésticas. Por otro lado, los restos de desechos encontrados en los rellenos podría suponer la existencia de viviendas al interior de los recintos o en sus alrededores, pero esto no es así, todo indica que los lugares de habitación estaban en otras zonas. 
Asimismo, las excavaciones en el patio hundido han mostrado la existencia de al menos dos espacios diferenciados, pero estrechamente vinculados entre sí. Esto se deduce a partir de la información registrada en la capa $\mathrm{C}$, en donde la presencia de un gran fogón indica que el lado Norte del patio estaba destinado a una función de quema o cocción particular, mientras que el resto del patio estaba limpio y sus lados protegidos con arena fina. La suma de las evidencias permite sugerir que se trataba de un espacio especial al cual el acceso habría sido restringido.

Por otra parte, sobre el lado Este del edificio había una terraza antigua que habría formado parte de un patio abierto por sus lados Este y Norte. La terraza estaba limpia y bien cuidada, sin deshechos, fogones u otros elementos extrańos a su composición fundamental (tierra y yeso), que revelen su verdadera función, por lo que se puede pensar que se trataba de una zona de reuniones, de espera $\mathrm{u}$ otra actividad. Asimismo, parece que es por esta zona por donde se ingresaba al recinto, pasando por el lado Este de la plataforma occidental hasta llegar al patio hundido. Se ha remarcado que los muros de contención de la plataforma (muro E2 y muros de la esquina noreste del patio hundido) son los más bajos y solamente tienen 30 centímetros de altura. El acceso al patio por los otros tres lados de la plataforma (lados oeste, norte y sur) es más difícil debido a que se encuentra a una altura promedio de 80 a 90 centímetros sobre el nivel del terreno.

Vistos en conjunto, los rasgos arquitectónicos — patio hundido y plataformas - y la presencia de contextos rituales (el fogón y las ofrendas), sugieren que las construcciones tenían una función ceremonial, tal vez también relacionada con actividades productivas. Al mismo tiempo, las excavaciones han permitido conocer que la primera ocupación de este sector y de todo el sitio se relaciona con la fase Pinta. Esto refuerza la hipótesis de que es a partir de la fase Pinta que se inició la construcción de edificios o construcciones monumentales en el valle de Chincha (Lumbreras 1987a, 2008; Canziani 1992, 2009), aunque de acuerdo con el desarrollo Paracas observado en otros valles como Ica, Palpa y Nasca (Reindel e Isla 2006) es posible sugerir que este proceso empezó antes en el valle.

\section{La cerámica}

El inventario de la cerámica recuperada en las excavaciones comprende 1520 fragmentos, de los cuales solo el 13\% corresponde a fragmentos diagnósticos (bordes, bases, cuerpos, etc.) y el 77\% a fragmentos no diagnósticos. El análisis realizado es de tipo macroscópico y ha sido basado principalmente en la clasificación funcional propuesta por Lumbreras (1984, 1987b) y en la clásica propuesta de Shepard (1956) para la definición de formas, técnicas de decoración y atributos estructurales (cuerpo, abertura, base, etc.). En todo el proceso de clasificación y análisis se tuvo en cuenta la procedencia — el contexto- de los fragmentos para no perder de vista aspectos cronológicos y funcionales 5 .

Aunque la muestra de fragmentos diagnósticos es bastante limitada, el análisis realizado nos ha permitido reconocer una variedad de vasijas abiertas y cerradas que representan un corpus bastante completo de la cerámica de la época, la cual, como se dijo al inicio, se relaciona totalmente con la fase Pinta del valle de Chincha, equivalente con la ocupación Paracas Tardío (Ocucaje 8).

\subsection{Formas de las vasijas}

De acuerdo con la clasificación funcional, la muestra fue dividida en dos grandes grupos: vasijas abiertas y vasijas cerradas. Esta división se hizo según su función primaria de contener sólidos o líquidos y en base al cruce de dos atributos estructurales: la forma de abierta o cerrada y la relación de proporciones entre el cuerpo (altura y diámetro) y la abertura (alto y ancho). En este primer nivel de análisis se han identificado las formas (clases) básicas: platos, cuencos, tazones, boles, ollas, cántaros, botellas, urnas, etc. En un segundo nivel de análisis se han identificado todas las formas de vasijas presentes en cada clase, que serían las variantes de forma, las mismas que han sido diferenciadas por sus atributos y rasgos estructurales internos. 
De este modo, entre las vasijas abiertas destacan los platos que representan el 5\% de la muestra, los cuencos — con dos subclases: cuencos bajos (35\%) y cuencos altos (11\%) - que representan el 46\% de la muestra y los tazones que representan el 8\% de la muestra (Fig. 11), además de sus respectivas variantes. Entre las vasijas cerradas destacan notoriamente los boles - pequeños recipientes de contorno esférico de paredes delgadas y usualmente con decoración incisa-, los cuales representan el $12 \%$ de la muestra, las ollas sin cuello y las ollas con cuello que representan el $22 \%$ de la muestra, y en menor porcentaje los cántaros y botellas, cada una representando el $3 \%$ de la muestra (Fig. 12).
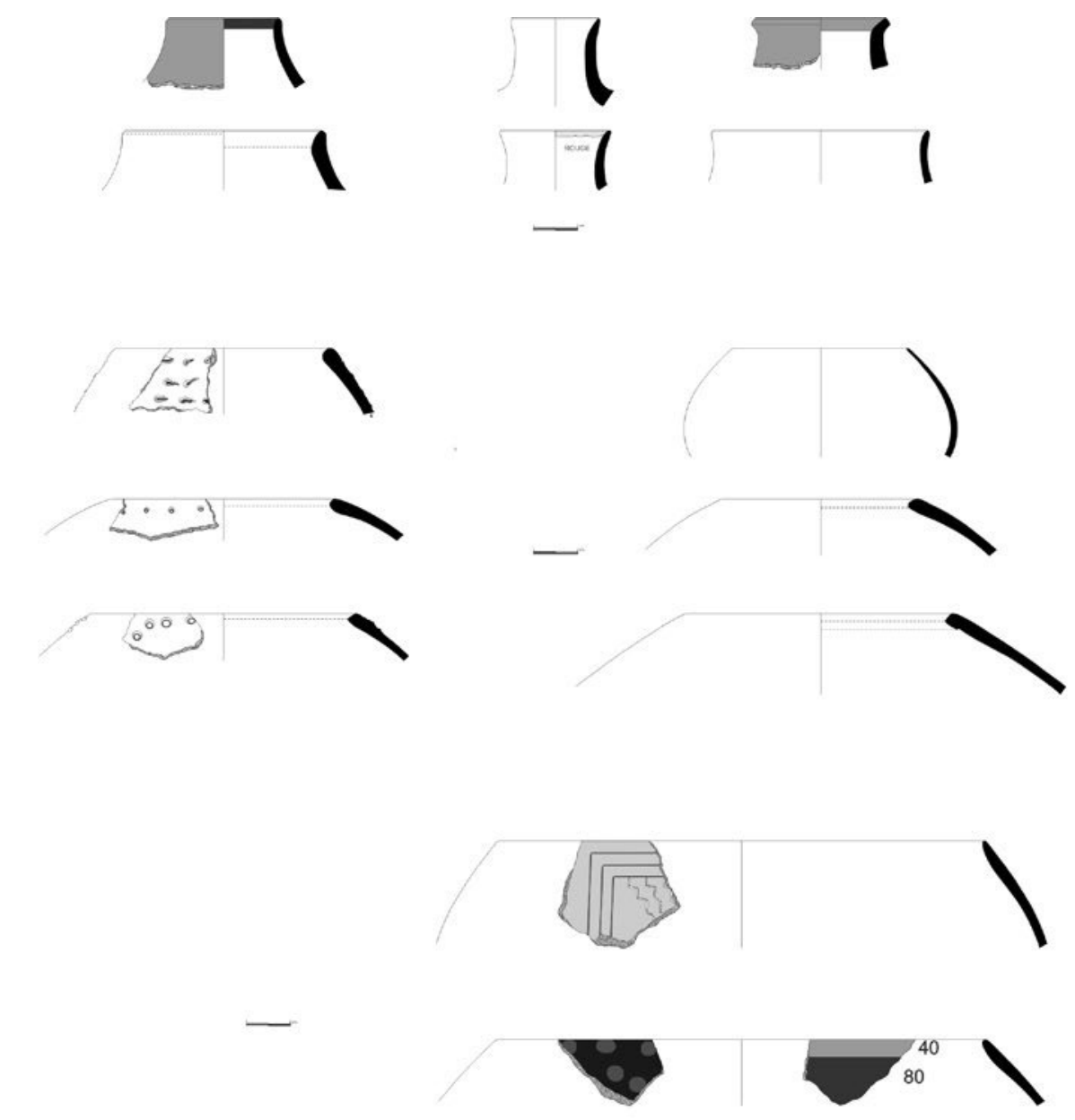

LEYENDA :
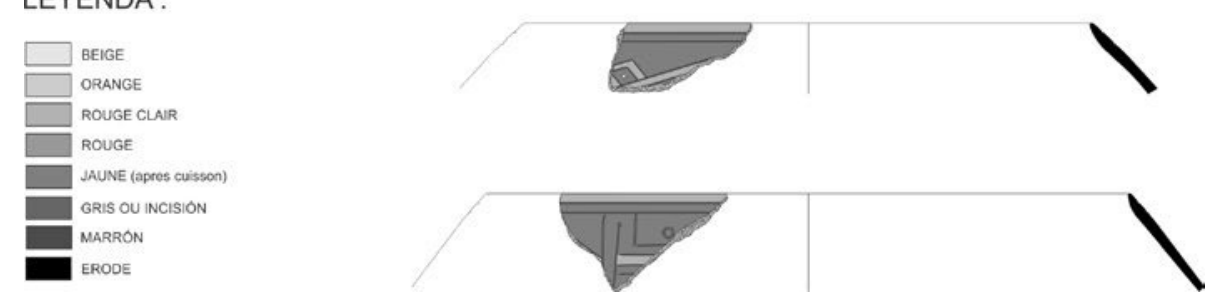

Figura 11. Dibujo de cerámica con ejemplos de las formas de vasijas abiertas, entre las que destacan claramente los cuencos -altos y bajos_y los tazones. 


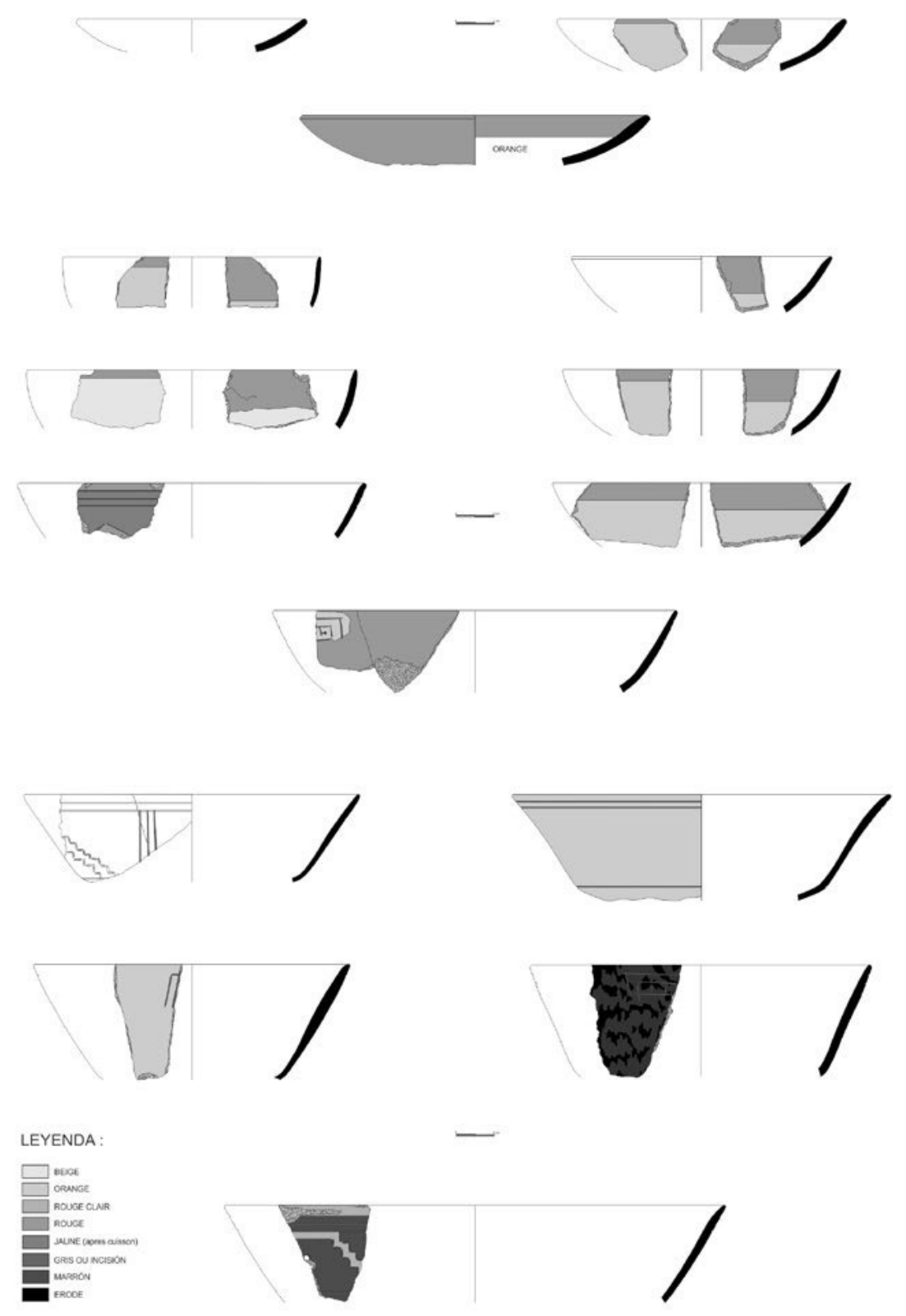

Figura 12. Dibujos de cerámica con ejemplos de las formas de vasijas cerradas, en donde se observa una gran variedad de formas cerradas de uso no doméstico. 
Como ya se dijo antes, en cada una de las principales formas de vasijas se han llegado a distinguir detalles en el grosor e inclinación de las paredes, presencia o no de ángulo basal, o diferencias en el acabado de los bordes que nos remiten a variantes de formas que en este caso no es necesario detallar.

\subsection{El proceso de fabricación}

En el análisis de la materia prima utilizada en la fabricación de la cerámica de El Mono, se distinguen tres tipos de pasta:

a) Pasta de grano fino de textura compacta y poco porosa cuya granulometría varía entre 0.1 y 0.2 milímetros, en la cual se agregó arena muy fina como desgrasante, así como también cuarzo en polvo, pirita, como también puntos blancos (feldespato) y mica en porcentaje reducido. Este tipo de pasta está presente en $40 \%$ de la muestra analizada, especialmente en las vasijas abiertas (platos y cuencos) y también en los boles y botellas.

b) Pasta de grano medio de textura semicompacta y porosa cuya granulometria varía entre 0.2 y 0.5 milímetros, en donde se incluye arena de grano medio como desgrasante principal, además de cuarzo en polvo, pirita y puntos blancos que pueden corresponder a feldespato. Esta pasta se encuentra en $42 \%$ de la muestra, principalmente en los cuencos, algunas ollas y cántaros de acabado más fino.

c) Pasta de grano grueso de textura semicompacta y porosa cuya granulometria varía entre 0.5 y 1 milímetros de grosor. Los desgrasantes observados son arena de grano grueso, cuarzo molido de grano medio, pirita y piedrecillas, así como inclusiones de puntos blancos (feldespato) y mica, además de un poco de conchas molidas. Este tipo de pasta se presenta en el 18\% de la muestra y de preferencia en las ollas y en menor porcentaje en los cuencos y cántaros.

En cuanto a la técnica de elaboración de la cerámica, debemos indicar que, si bien se requiere de métodos e instrumentos más precisos para su identificación, en nuestro análisis hemos llegado a observar trazas dejadas al momento de la fabricación de los recipientes que indican de manera clara que las vasijas fueron hechas con la técnica del enrollado o coiling. Esta técnica, que parece haber sido la más empleada, necesita de un plato de alfarero que es utilizado como soporte, a la manera de un torno, sobre el cual el alfarero da forma al recipiente (Carmichael 1990: 278-290). De manera adicional se debe mencionar al estirado y modelado, esta última utilizada en combinación con las dos primeras (Carmichael 1986).

Con respecto al acabado de las superficies, en todos los casos, pero especialmente en las vasijas abiertas, se observa un proceso que incluye el alisado húmedo hecho a mano, el gratado y el pulido; mientras que en las vasijas cerradas se observa solo el alisado aplicado en la parte superior del cuerpo y en el cuello. El alisado húmedo fue una de las técnicas más utilizadas, especialmente en los objetos con superficies decoradas y objetos de servicio (platos, cuencos, tazones, boles y en la parte externa de botellas). Por otro lado, en casi toda la muestra se observa la aplicación de una capa de engobe, la cual ha sido bien lograda. Es importante señalar que, en el caso de las vasijas abiertas, el engobe ha sido aplicado cuidadosamente en los dos lados logrando así superficies bastante lisas. Finalmente, la mayor parte de las vasijas presentan un buen pulido, especialmente las vasijas abiertas, en donde al menos el $85 \%$ de la muestra tiene este tipo de acabado. En el caso de las vasijas cerradas el pulido se observa en los boles y botellas. El pulido en algunos casos es de buena calidad y puede ser considerado como una técnica decorativa porque presenta superficies contrastadas con brillos marcados y tonos opacos.

Finalmente, en cuanto a la cocción de las vasijas hemos podido verificar mayormente la utilización de hornos de atmosfera oxidante y en muy pocos casos hornos de atmosfera reductora. En tal sentido, las vasijas se caracterizan por presentar una pasta de color naranja y marrón de tonos variados. Aunque la cocción de las vasijas fue bastante bien lograda, numerosos fragmentos presentan defectos de cocción — núcleo gris o manchas oscuras en diferentes partes del cuerpoque indican una oxidación incompleta o parcial de la cerámica. 

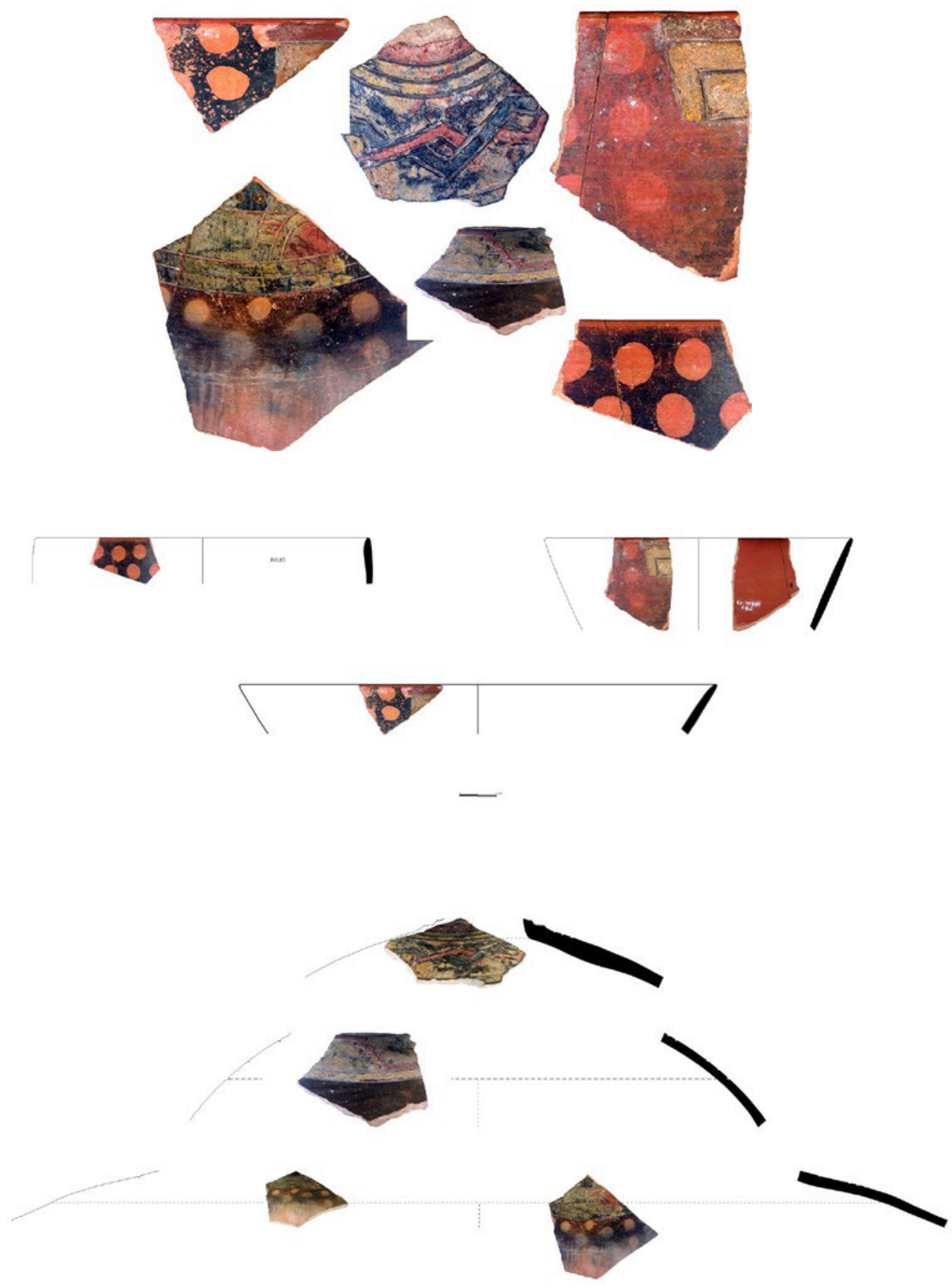

Figura 13. Algunos ejemplos de fragmentos de cerámica Paracas de la fase Pinta, la cual muestra rasgos comparables con la fase Ocucaje 8 del valle de Ica. 


\subsection{La decoración}

Hemos identificado una variada gama de técnicas decorativas de las vasijas, entre las que destacan la pintura positiva, la pintura poscocción con motivos simples y geométricos, la incisión, la decoración negativa y con menos frecuencia la impresión y la escisión, todas estas técnicas, con excepción de la pintura poscocción, fueron aplicadas antes de la cocción (Fig. 13). Hemos reconocido también la recurrencia de una o varias técnicas decorativas en relación con una o dos formas de vasija en particular, las cuales se describen a continuación.

La pintura positiva. De uso muy frecuente en la época Paracas. Se limita a una banda ancha dispuesta en forma horizontal en el borde interior o exterior de los cuencos. No es frecuente en los cuencos altos, en donde usualmente sirve de base para la aplicación de la pintura poscocción. Los colores más usados son el rojo, el beige y el anaranjado. Se debe señalar que el color negro presente en algunas superficies no es una pintura de tipo positivo, sino que ciertos ceramios fueron ahumados después de la cocción.

La pintura poscocción. Esta técnica decorativa es un rasgo típico de la cerámica Paracas. La pintura, compuesta por resinas de diversos colores, el amarillo y el rojo — los más frecuentes-, el verde y el gris - los más raros-, fueron aplicados en capas espesas sobre superficies usualmente delimitadas por líneas incisas. Se encuentra exclusivamente asociada a los boles (los más grandes), cuencos altos, platos y botellas.

La incisión. Es una técnica decorativa característica de la vajilla Paracas. La muestra presenta dos tipos de incisión; cortante (en "V») y no cortante (en «U»), ejecutadas respectivamente con un instrumento de punta fina o sin punta sobre una pasta blanda. Es una técnica claramente asociada a los platos, cuencos altos, boles y botellas, sobre las cuales se formaron motivos geométricos lineales simples, en paneles y escalonados y de líneas paralelas. Está asociada con la pintura post cocción y la decoración en negativo. Pocas veces se presenta en forma independiente.

La impresión. Técnica poco presente en la muestra y usualmente se utilizó para hacer círculos profundos y también algunos motivos escalonados que con frecuencia se confunden con las incisiones. Se encuentra asociada a ollas en donde se presenta en forma de puntos o círculos poco profundos.

La decoración en negativo. Es otra técnica bastante difundida en la cerámica Paracas. El diseño en negativo fue obtenido por el método de la cera perdida. La encontramos sobre la superficie externa de las vasijas y los motivos más frecuentes son los círculos de color naranja (color natural de la pasta o del engobe) sobre fondo de pintura negra. La decoración en negativo se presenta sola o en asociación con la pintura poscocción y las incisiones, y se encuentra en platos, cuencos altos, boles y raramente sobre botellas.

En general, estas técnicas decorativas se encuentran frecuentemente asociadas a los platos, cuencos altos, tazones, boles de talla grande y botellas; siendo menos usadas en ollas y aún más raras en los cántaros. Los diseños figuran generalmente sobre la superficie exterior de los ceramios, con excepción de los platos ralladores en donde están en su interior. Hay algunas vasijas que combinan hasta tres técnicas decorativas: la incisión, la pintura poscocción y la decoración negativa. En el caso de los cuencos los diseños usualmente se presentan en el borde exterior de las vasijas, dispuestos en todo el contorno o en paneles. Los motivos representados son mayormente de tipo geométrico, con rasgos angulosos, entre las que se encuentran líneas simples o paralelas, círculos solos o con puntos, escalonados, grecas, rombos, dameros, etc. Un motivo que destaca entre todos es la greca entrelazada de tres bandas que forman rombos y con puntos al centro.

En resumen, podemos decir que la cerámica del sitio El Mono tecnológicamente es de buena factura, lo cual se observa en la uniformidad de las formas - y sus variantes_- la homogeneidad de sus proporciones, la destreza en la ejecución de los diseños, etc., lo que demuestra que los ceramistas habían alcanzado un buen grado de especialización además de un evidente sentido artístico. 


\section{Recursos de subsistencia}

Las excavaciones en este montículo C1 del sitio El Mono nos han permitido recuperar una importante cantidad de recursos de subsistencia, entre los que destacan principalmente restos de plantas cultivadas que fueron analizados por Elia Centurión (ms.) y también diversos recursos marinos que fueron analizados por Manuel Gorriti (ms.), con una menor presencia de huesos de animales.

Entre las plantas cultivadas destaca principalmente el maíz (Zea mays) con más de dos variedades, seguido del pallar (Phaseolus vulgaris), el pallar de los gentiles (Canavali plagiosperma), la calabaza (Lagenaria siceraria), aji (Capsicum, sp.), el frejol (Phaseolus lunatus) y la achira (Canna edulis). Entre las plantas cultivadas de uso artesanal se encuentra el algodón (Gossypium barbadense). También se han identificado plantas frutales como el pacae (Inga feuillei) y la guayaba (Psidium guayava), así como también otras plantas silvestres como la caña brava (Gynerium sagitatum) y la Tillandsia sp. Al respecto, se debe indicar que el valle de Chincha posee suelos ricos y propicios para la agricultura, lo que lo que ha debido optimizar la producción. Es muy posible que los canales de riego identificados en el valle que se relacionan con los períodos Topará y Carmen, también sean de esta época e incluso anteriores.

Los recursos marinos también son abundantes y variados. Se tienen principalmente moluscos de talla pequeña, entre los que se encuentran choros (Choromitylus chorus), almejas (Donax obesulus) Protothaca thaca, Mulinia edulis, Smimytilus algosus, Fissurella sp., Prisogaster niger y crustáceos. La explotación de estos recursos se realizó en dos zonas del litoral: en playa arenosa y en litoral rocoso. Llama la atención la ausencia de restos de huesos de pescado, aunque parece que esto sucede en la mayoría de sitios excavados en la costa, lo que no quiere decir que estaban ausentes en la dieta.

En contraste, los restos animales están poco representados. En general, hemos recuperado mayormente fragmentos de huesos pertenecientes a animales pequeños, como aves y cuyes. También hallamos un pedazo de mandíbula con sus molares in situ que puede pertenecer a un camélido. La confirmación de la presencia de restos de camélidos (huesos, lana bajo forma de fibra) en otros contextos Paracas de la época (Mader et al. 2018) indica que ya en ese tiempo había claros contactos con poblaciones de la sierra.

De manera general, lo que nos indican las evidencias registradas, es que los habitantes del lugar tenían una dieta rica y variada. Evidentemente todavía se necesita contar con una mayor base de datos al respecto, pero si se compara con sitios contemporáneos en otros valles resulta evidente que esto fue así.

\section{Artefactos y otros objetos}

En las excavaciones, especialmente en las varias capas de relleno, además de fragmentos de cerámica también se han recuperado diversos objetos y artefactos de uso artesanal, entre los que destacan fragmentos de textiles, cuentas de moluscos, artefactos de madera, etc., algunos de ellos encontrados en contextos de ofrenda.

Los restos de textiles no son abundantes, pero son variados y tienen una presencia significativa. Estos incluyen hilos de algodón de varios colores (rojo, amarillo, blanco, marrón, ocre, entre otros), fragmentos de diversos tejidos llanos con diseños simples, así como fragmentos de redes anudadas que podrían corresponder a redes de pesca. Se remarca particularmente la producción y el uso del algodón, de cuya planta recolectamos sus semillas, sus tallos y los copos con sus fibras. También se recuperaron pequeñas cańas con hilos de colores enrollados alrededor. El uso de la fibra vegetal fue igualmente intenso, habiéndose encontrado pedazos de cuerdas que en algunos casos estaban anudados. Las fibras vegetales fueron utilizadas principalmente para la confección de cestas, pero también como «mortero», mientras que algunas piedras envueltas con fibras de achira se hallaron formando parte de algunos muros. 
Entre otros hallazgos más significativos destaca de forma particular una acumulación de cuentas hechas en valvas de Donax obesulus, que parecen ser parte de un collar y que fue registrada en el patio hundido. Entre los objetos de madera se registró algunos trompos o conos tallados, más conocidos como «flotadores», aunque dicho nombre no esté necesariamente relacionado con su verdadera función. También se hallaron varios «paquetes» o «envoltorios» de cabellos humanos que tendrían relación con el carácter religioso del edificio. Por último, no podemos dejar de mencionar el particular interés que tenían los habitantes de ese tiempo por los excrementos humanos, los cuales eran depositados en forma "especial» junto a las ofrendas, en los rellenos, o como ocurrió en el caso del Edificio B, donde se halló en asociación con dos bellos cestos Paracas Cavernas (Lumbreras 1985: 44).

\section{Contextos de ofrenda}

Las excavaciones nos han permitido registrar diversos objetos depositados en las capas de relleno o al interior de pequeños hoyos excavados en la capa natural, tanto en el patio hundido como delante de la plataforma sudeste. Estos objetos han sido considerados como ofrendas debido a su deposición manifiestamente intencional. Seguidamente se describen los hallazgos más representativos:

a. Pequeña acumulación de tierra de unos $15 \mathrm{~cm}$ de diámetro en cuyo interior se encontró un paquete de cabellos y otro de vegetales, así como un fragmento de calabaza, un fragmento de tejido y un fragmento de cerámica incisa, todo lo cual estaba cubierto por la base de un plato (Elemento T-308K).

b. Pequeña concentración de hojas — al parecer coca (Erythroxylon sp.) — mezclada con tierra, tenía unos 9 centímetros de diámetro y 7 centímetros de espesor (Elemento T-307L).

c. Concentración de «choritos» (Perumytilus purpuratus) mezclados con restos vegetales, que estaban depositados al interior de un pequeño pozo de 16 por 22 centímetros de lado y 30 centímetros de profundidad (Elemento T-305J). Cabe indicar que la mayoría de «choritos» estaban con las valvas cerradas.

d. Se trata de un pozo irregular de unos 45 centímetros de diámetro y 25 centímetros de profundidad, el cual estaba rellenado con tierra arenosa. En el fondo de dicho pozo se había depositado una pequeña laja cubierta por un gran fragmento de cerámica, sobre el cual se encontró un fragmento textil, algunos moluscos y restos vegetales (elemento T-305I).

e. Pequeño pozo de unos 30 centímetros de diámetro y 35 centímetros de profundidad rellenado con tierra arenosa, cuya parte superior estaba cubierta por dos lajas. En el fondo se habían depositado dos grandes fragmentos de cerámica llana (elemento T-312J).

Estos contextos nos revelan el desarrollo de actividades de carácter ritual en el sitio. Por un lado, es probable que estas ofrendas hayan sido depositadas en momentos relacionados con la construcción del edificio (al interior de los rellenos), mientras que, por otro lado, las ofrendas halladas al interior de los pisos (hoyos excavados en la capa natural) habrían sido depositadas durante el uso de las estructuras arquitectónicas. Cabe señalar que ciertos moluscos, como aquellos del género Mytilus y Pecten, eran altamente considerados en los rituales del mundo andino (Lumbreras 1974: 59).

\section{Análisis y discusión}

Las investigaciones realizadas en el sitio arqueológico El Mono, a través de una excavación metódica y rigurosa, nos han permitido realizar un estudio bastante detallado del edificio $\mathrm{C} 1$ con la finalidad de cumplir con nuestros objetivos que, en su conjunto, planteaban hacer una reconstrucción de la historia particular del sitio y del rol que desempeñó en el desarrollo cultural del valle de Chincha y de los valles vecinos. 
$\mathrm{Al}$ analizar las investigaciones realizadas sobre la cultura Paracas, se observa que gran parte de ellas se basaron en el estudio de materiales cerámicos procedentes de colecciones particulares y de recolecciones de superficie. En consecuencia, son pocos los datos procedentes de excavaciones científicas con verdaderos contextos y asociaciones que permitan realizar interpretaciones más cercanas al proceso de desarrollo cultural Paracas. Si bien Wallace realizó excavaciones en tres sitios del valle de Chincha, lo que le permitió proponer la primera secuencia cronológica para dicho valle, estas fueron de pequeña escala y por tanto resultaba necesario realizar excavaciones más grandes (en área) para verificar sus planteamientos, algo que todavía está pendiente a pesar de nuestras excavaciones. Sin embargo, reconocemos que los trabajos de Wallace constituyeron un primer intento para construir una secuencia cultural del valle sobre el cual se apoya nuestro estudio.

El edifico $\mathrm{C} 1$ es un representante del desarrollo regional de las últimas fases de la cultura Paracas en el valle de Chincha y la cerámica encontrada, único marcador cronológico con el que contamos, nos permitió saber que el sitio estaba asociado a una ocupación relacionada con la fase Pinta. Todos los elementos expuestos muestran igualmente que esta ocupación ocurrió durante un solo período de tiempo, que en términos cronológicos fue breve y que se puede situar alrededor del año 300 a.C. Este período se corresponde con la fase Ocucaje 8 del valle de Ica (Menzel et al. 1964). Por otro lado, el edificio B también tiene ocupación Pinta y una reocupación del período Topará (Lumbreras 1985). En lo que concierne a la fase más antigua (Pozuelos), es posible que no haya tenido una ocupación intensa y a eso se debería su ausencia. Incluso Menzel (1971) indica que dicha fase fue aislada en base a muy pocos materiales. Tal vez Pozuelos corresponde a una ocupación más rural, pero eso es un tema a investigar.

La exposición de las estructuras arquitectónicas en el sitio ha confirmado en gran parte nuestras hipótesis iniciales de trabajo, lo que nos permitió definir que el edificio estaba conformado por dos plataformas y una terraza. Una de las plataformas presenta un patio hundido. Estas estructuras han sido construidas en dos etapas sucesivas. Vista en conjunto, la arquitectura no es muy elaborada y parece relativamente modesta en tamaño si se la compara con otras construcciones de la época presentes en los valles de la costa central o norte del Perú.

Las técnicas de construcción también son simples y se basan en la utilización de piedras y barro para la construcción de los muros de contención de las plataformas. El mortero estaba compuesto por barro mezclado con paja y en ciertos casos de hojas de achira. Si bien los muros tuvieron un acabado, estos se muestran toscos y sin un buen acabado superficial.

En cuanto a su función, podemos decir que el sitio no tuvo una ocupación de tipo doméstico o habitacional, notándose la ausencia de un uso prolongado de los pisos los cuales por el contrario se hallaron limpios. Si nuestras hipótesis son correctas, más bien se trataría de un edificio público de posible uso ceremonial. Sus componentes morfoestructurales nos permiten plantear que se trata de un pequeño templo, que presenta al menos dos espacios diferentes, pero estrechamente vinculados entre sí: por un lado, el patio hundido, zona especial con acceso restringido a un número limitado de personas y directamente relacionado con la capa $\mathrm{C}$ y al fogón; y la terraza antigua, que probablemente fue una zona destinada a reuniones, espacio de espera, etc. Las ofrendas halladas en los diversos contextos nos permiten sustentar la existencia de actividades que podemos llamar de carácter ritual. Estas actividades fueron seguramente relacionadas con la construcción de los componentes estructurales del edificio y con las actividades que allí se realizaban.

Con respecto a su integración con los otros sectores del sitio, hemos establecido una relación directa con el edificio $\mathrm{B}$, el cual también está asociado con una ocupación de la fase Pinta. Asimismo, podemos decir que sus elementos estructurales, técnicas de construcción, etc., son de similar manufactura que los del edificio C1. Entonces las dos estructuras habrían sido ocupadas simultáneamente, siendo tal vez el edificio C1 el más antiguo.

La abundancia de plantas cultivadas y la gran variedad de las mismas, indica que la agricultura fue practicada de manera intensa, aunque todavía no se ha identificado ningún canal de irrigación 
de esa época. No obstante, pensamos que la población debió practicar la irrigación y es posible que ellos fueran los constructores de uno de los canales que pasan por la proximidad del sitio. Por otra parte, podemos agregar que el establecimiento del sitio en una zona de acceso directo a las extensas zonas fértiles de cultivo del valle bajo, parece otorgarle una cierta importancia estratégica.

Paralelamente, el estudio de la cerámica ha expuesto importantes informaciones sobre su manufactura y sobre la habilidad artística de los antiguos ceramistas paracas. Sin embargo, todavía nos quedan por efectuar otros análisis, entre ellos, el análisis químico y mineralógico, análisis petrográfico, estudios con rayos X, etc., los que nos pueden ayudar a determinar con mayor precisión el proceso de producción de la cerámica, así como el uso y función de la misma.

En cuanto a las actividades económicas y productivas, debemos resaltar la importancia que tuvo la actividad textil, para la cual utilizaron fibras vegetales y algodón de variados colores, así como posiblemente la lana de camélidos. También se puede indicar que hubo una intensa explotación de los recursos del mar, cuyos restos hallados están conformados por variadas especies de moluscos. Este recurso constituyó una fuente fundamental de alimentación de las poblaciones tempranas. Queda todavía por estudiar las implicancias que tuvo el manejo de estos recursos en la organización del trabajo, entre otros aspectos del proceso productivo de la población paracas de la fase Pinta.

\section{Comentarios finales}

Después de los trabajos casi pioneros y científicamente rigurosos realizados por el Proyecto Arqueológico Histórico Chincha-Pisco en el valle de Chincha, en los últimos años se han realizado otras investigaciones, siendo las más recientes los trabajos de José Canziani (1992, 1994, 2009, 2013) sobre la arquitectura Paracas y los de Charles Stanish y Henry Tantaleán en el sitio Cerro del Gentil (Tantaleán et al. 2013, 2017). Lo interesante de este sitio, es que se encuentra situado en una zona muy próxima a El Mono y sobre la misma plataforma geológica. En Cerro del Gentil se recuperaron materiales de la fase Pinta, corroborando así los antiguos planteamientos de Wallace sobre la presencia de esta fase en la secuencia cronológica del valle de Chincha. Por su parte Lumbreras, a partir de los vestigios de superficie como la cerámica y las características arquitectónicas asociadas, suponía que este montículo pertenecía a la época Paracas Cavernas y que por tanto era contemporáneo con El Mono.

En este sentido, varias hipótesis parecen irse confirmando. Estos sitios son contemporáneos y fueron ocupados durante la fase Pinta, al menos en una época. Arquitectónicamente tienen la misma manufactura, aunque con dimensiones diferentes, siendo Cerro del Gentil el más grande y el de mayor importancia en este sector del valle. En cuanto a la función, hemos visto que no fueron ocupados con fines domésticos sino más bien parecen estar relacionadas con actividades de carácter público. El Mono B parece que fue un recinto destinado al almacenaje de alimentos y vegetales. El Mono C1, montículo de dimensiones modestas al que llamamos «templo», parece haber estado dedicado a actividades de tipo ritual. Por su parte Cerro del Gentil, parece ser un asentamiento en el que fueron enterrados personajes que gozaban de un alto estatus dentro de la sociedad. Si se trata del mismo grupo étnico - Paracas, de la fase Pinta — que ocupaba ambos sitios simultáneamente, las evidencias revelan que estos sitios habrían funcionado como centros públicos menores, cuya función de sus ocupantes sería intermedia entre la de aquellos que se ocupaban los grandes edificios del valle bajo y los pobladores que realizaban labores primarias y que ocupaban los poblados rurales del valle medio-alto (Canziani 2009: 168-169).

La gran cantidad de restos materiales (vegetales, cerámica, moluscos, etc.) hallados en los rellenos constructivos del sitio El Mono muestran que sus ocupantes estaban en relación con poblaciones dedicadas principalmente a la actividad agrícola y en menor grado con la pesca. Asimismo, la producción artesanal de cerámica, textiles y otros artefactos indica la presencia de grupos con un cierto nivel de especialización. Queda por estudiar la problemática relacionada con la ocupación 
doméstica o rural, ya que son pocos los sitios de este tipo registrados en el valle, los cuales al parecer se localizan mayormente en la parte alta del valle. No obstante, es posible que sitios de este tipo debieron estar situados cerca de los monumentos, en lo que hoy corresponden a las zonas de cultivo, por lo que es casi seguro que han desaparecido.

Con las informaciones obtenidas hasta hoy en Chincha, es posible que ya se pueda realizar el estudio de los asentamientos desde una perspectiva general, comenzando por el valle medio-alto y proponer nuevas hipótesis que ayuden a resolver numerosas interrogantes, entre otros, por ejemplo: cuáles fueron las condiciones iniciales que permitieron el desarrollo urbano en Chincha y si fue con la fase Pinta que se inició la construcción de los edificios públicos, como lo propuso Lumbreras en sus numerosas hipótesis de trabajo. Investigar también sobre la naturaleza de los numerosos sitios con rasgos Pinta, ubicados por el PAHChP (cerámica y adobitos) en otras partes del valle y principalmente en el valle bajo, entre los que se encuentran las huacas Santa Rosa, Limay, Alvarado, Los Hoyos, Pampa de Portachuelo, entre otras. (Lumbreras 1987).

Finalmente, también queda por entender cuál fue el rol de los asentamientos Paracas Tardío (fases Pinta y Topará) frente al inmenso material Paracas Cavernas y Paracas Necrópolis descubiertos por Julio C. Tello en la península de Paracas (Tello 1928, 1929, 1959; Tello y Mejía 1979). En este caso, Lumbreras pensaba, a manera de hipótesis, que las personas enterradas en la península corresponderían a personajes de alto estatus de la sociedad que vivían en el valle de Chincha y también en Pisco (Lumbreras, comunicación personal 1987).

Estas y muchas otras preguntas quedan aún por resolver. Por el momento, los datos aquí presentados constituyen un pequeño aporte en esa dirección y siguen siendo una fuente de motivación para seguir por este camino.

\section{Notas}

1 El sitio fue bautizado como el Mono en 1985, aunque posteriormente se comenzó a utilizar el nombre de Chococota, pues era el canal más próximo al sitio. Para evitar confusiones en este trabajo optamos por la primera opción.

2 Para una mejor referencia sobre la cronología de la cultura Paracas ver Unkel et al. 2007.

3 En Chincha Wallace realizó excavaciones mediante dos pozos de sondeo de 2 metros por 2 metros en dos sitios del valle, a partir de los cuales elaboró una secuencia para el Horizonte Temprano que está sustentada principalmente en la interpretación de la variación de los estilos y no tanto en la información estratigráfica. En tal sentido, sus proyecciones iniciales necesitan verificación mediante excavaciones más amplias.

${ }^{4}$ Aquí se mantiene la denominación original de este rasgo como capa C (Isla 1992: 34-35) aunque se debe indicar que no se trata de una capa propiamente dicha.

5 Detalles técnicos y metodológicos del análisis de la cerámica procedente del sitio El Mono se puede ver en Isla 1992: 50-65.

\section{REFERENCIAS}

Canziani, J.

1992 Arquitectura y urbanismo del período Paracas en el valle de Chincha, Gaceta Arqueológica Andina 22: 87-117, Instituto Andino de Estudios Arqueológicos (INDEA), Lima.

1994 Arquitectura monumental Paracas en el valle de Chincha, 1/2 de Construcción. Revista de Diseño y Construcción 96, 21-24, Lima.

2009 Ciudad y territorio en los Andes: contribuciones a la historia del urbanismo prehispánico, Fondo Editorial PUCP, Lima. 
Canziani, J. y C. del Águila

1994 Sistemas agrícolas de la época Paracas en el valle de Chincha. Perú, el problema agrario en debate. SEPIA 5, 613-636, Seminario Permanente de Investigación Agraria. Lima.

\section{Carmichael, P. H.}

1986 Nasca pottery construction, Nawpa Pacha 24, 31-48.

1990 Technologie de la cèramique Nasca. INCA-PERU, 3000 ans d' Histoire, 240-278, Mussées royaux dÀrt et d'Histoire, Bruxeles. https://doi.org/10.1179/naw.1986.24.1.002

\section{Centurión, C. E.}

ms. Informe técnico sobre el estudio de los restos botánicos procedente de las excavaciones en el sitio El Mono-Sector C1 (1992).

\section{Engel, F.}

1957 Early sites in the Pisco Valley of Peru: Tambo Colorado, American Antiquity 23 (1), 34-45.

1963 Notes relatives à des explorations archéologique à Paracas et sur de la côte du Pérou. Travaux de l'Institut Français des Études Andines 9, 1-72.

1966 Paracas: cien siglos de cultura peruana, Librería Editorial Juan Mejía Baca, Lima.

\section{Gorriti, M. M.}

ms. Informe sobre el análisis de los restos malacológicos encontrados en las excavaciones en el sitio El MonoSector C1 (1992).

Kroeber, A. L.

1944 Peruvian archaeology in 1942, Viking Fund Publications in Anthropology, vol. 4, Wenner-Gren Foundation for Anthropological Research, New York.

1953 Paracas Cavernas and Chavín, University of California Publications in American Archaeology and Ethnology 40 (8), 313-348, Berkeley.

\section{Kroeber, A. L. y W. D. Strong}

1924 The Uhle Pottery Collections from Chincha, University of California Publications in American Archaeology and Ethnology 21(1), 1-54, University of California Press, Berkeley.

Lanning, E. P.

1960 Chronological and cultural relationships of early pottery styles in Ancient Peru, tesis de doctorado, Department of Anthropology, University of California, Berkeley.

Lumbreras, L. G.

1974 The peoples and cultures of ancient Peru [traducción de B. J. Meggers], Smithsonian Institution Press, (7ma edición, 1987), Washington, D.C.

1981 Arqueología de la América andina, Editorial Milla Batres, Lima.

1984 El criterio de función en Arqueología (II), Gaceta Arqueológica Andina 1(9), 3, Instituto Andino de Estudios Arqueológicos (INDEA), Lima.

1985 Informe preliminar sobre el estudio del sitio arqueológico «El Mono» (Sector B), valle de Chincha. Informe de las excavaciones realizadas en 1985, presentado al Instituto Nacional de Cultura (Proyecto Arqueológico Histórico Chincha-Pisco), Lima.

1987a Valle de Chincha: La Fase Pinta. Informe de investigación presentado al Instituto Nacional de Cultura (Proyecto Arqueológico Histórico Chincha - Pisco), Lima.

1987b Examen y clasificación de la Cerámica, Gaceta Arqueológica Andina 2(13), 3-4, 31.

2008 La présence de Paracas a Chincha, en: D. Lavallée (ed.), Paracas: Trésors inédits du Perou ancient, 34-39, Musée du Quai Branly, París.

Mader, C., S. Hölzl, K. Heck, M. Reindel y J. Isla

2018 The llama`s share: Highland origins of camelids during the Late Paracas period (370 to 200 BCE) in south Peru demonstrated by strontium isotope analysis, Journal of Archaeological Science: Reports (20), 257-270. https://doi.org/10.1016/j.jasrep.2018.04.032

Massey, S. A.

1986 Sociopolitical change in the upper Ica Valley, B.C. 400 to 400 A.D.: Regional states on the south coast of Peru, tesis de doctorado, Department of Anthropology, University of California, Los Angeles.

1990 Paracas. Inca-Peru 3000 ans d' Historie: 144-154, Musées royaux d'Art et d'Histoire, Bruxelles. 
Menzel, D., J. H. Rowe y L. Dawson

1964 The Paracas pottery of Ica: A study in style and time, University of California Publications in American Archaeology and Ethnology, vol. 50, University of California Press, Berkeley/Los Angeles.

Menzel, D.

1959 The Inca occupation of the South Coast of Peru, Southwestern Journal of Anthropology 15(2), 125-142.

1971 Estudios arqueológicos en los valles de Ica, Pisco, Chincha y Cañete, Arqueología y Sociedad 6, 1-161.

ONERN (Oficina Nacional de Evaluación de Recursos Naturales)

1970 Inventario, evaluación y uso de recursos naturales de la costa: cuenca de los rios San Juan (Chincha) y Topará, vol. I, Instituto Nacional de Planificación, Lima.

Peters, A. H.

1987-1988 Chongos: sitio Paracas en el valle de Pisco, Gaceta Arqueológica Andina 2(16), 30-34.

2013 Topará en Pisco: patrón de asentamiento y paisaje, Boletín de Arqueología PUCP 17, 77-101.

Reindel, M. y J. Isla

2006 Evidencias de culturas tempranas de los valles de Palpa, costa sur del Perú, Boletín de Arqueología PUCP $10,237-283$.

Rowe, J. H.

1958 La seriación cronológica de la cerámica Paracas elaborada por Lawrence E. Dawson, Revista del Museo Regional de Ica, año IX (10), 9-21.

1960 Cultural unity and diversification in Peruvian archaeology. Men and cultures: Selected Papers of the Fifth Congress of Anthropological and Ethnological Sciences, 627-631. University of Pennsylvania Press, Philadelphia.

Shepard A. O.

1960 Ceramics for Archaeologist, Carnegie Institution of Washington (Publication 609), Washington, D.C.

Silverman, H. I.

1991 The Paracas Problem, Archaeological Perspectives, en: A. Paul (ed.), Paracas, art \& architecture. Object and context in South Coastal Peru, 350-416, University of Iowa Press, Iowa City.

2009 Comparaciones y Contrastes entre la Costa Sur y la Costa Central del Perú durante el Período Formativo, en: R. Burger y K. Makowski (eds.), Arqueología del Periodo Formativo en la Cuenca Baja de Lurin, 429-490, Fondo Editorial PUCP, Lima.

Strong, W. D.

1957 Paracas, Nazca and Tiahuanacoid Cultural Relationships in South Coastal Peru, Memoirs of the Society for American Archaeology 13, Salt Lake City.

Tantaleán, H., C. Stanish, M. Zegarra, K. Pérez y B. Nigra

2013 Paracas en el valle de Chincha: nuevos datos y explicaciones, Boletín de Arqueología PUCP 17, 31-56. https://doi.org/10.18800/boletindearqueologiapucp.201701.003

Tantaleán, H., C. Stanish, K. Pérez y A. Rodríguez

2017 Las ocupaciones Paracas y Topará en Cerro del Gentil, valle de Chincha, Boletín de Arqueología PUCP 22, 61-89.

Tello, J.

1987 Informe Preliminar sobre el estudio del Sitio Arqueológico "El Mono" (Sub-Sector A3), Valle de Chincha. Informe de las excavaciones realizadas en 1987, presentado al Instituto Nacional de Cultura (Proyecto Arqueológico Histórico Chincha-Pisco), Lima.

Tello, J. C.

1928 Los descubrimientos del Museo de Arqueología Peruana en la península de Paracas. En Atti del XXII Congresso Internazionale degli Americanisti I, 679-690, Roma.

1929 Antiguo Perú. Primera época. Editado por la Comisión organizadora del Segundo Congreso Sudamericano de Turismo, Lima.

1959 Paracas, Primera parte, Publicación del Proyecto 8b del Programa 1941-42 del Institute of Andean Research of New York. Empresa Gráfica T. Schench S.A., Lima. 
Tello, J. C. y T. Mejía Xesspe

1979 Paracas, Segunda Parte: Cavernas y Necrópolis, Universidad Nacional Mayor de San Marcos/The Institute of Andean research of New York, Lima.

Unkel, I., B. Kromer, M. Reindel, L. Wacker, G.A. Wagner

2007 A chronology of the pre-Columbian Paracas and Nasca culture in the South Peru based on AMS-14C dating, Radiocarbon 49, 551-564. https://doi.org/10.1017/s0033822200042466

Wallace, D.

1959 Informe de reconocimiento del valle de Chincha, Revista del Museo Regional de Ica, Año X (11), 31-40. Ica.

1963 Early Horizon ceramics in the Cañete Valley of Peru, Nawpa Pacha 1, 35-38. Berkeley.

1970a Informe del reconocimiento del valle de Chincha, Arqueología y Sociedad 2, 7-16.

1970b Trabajo de campo en la Costa Sur del Perú, Arqueología y Sociedad 2: 17-27.

1971 Sitios arqueológicos del Perú (Segunda entrega): valles de Chincha y Pisco, Arqueológicas 13.

1972 Sumario de la secuencia cultural de los valles de Chincha y Pisco (article mimeographié), 1-4, suit son rapport des Prospections (1971).

1985 Paracas in Chincha and Pisco: A reappraisal of the Ocucaje sequence, en: D.P. Kvietok y D. H. Sandweiss (eds.), Recent Studies in Andean Prehistory and Protohistory, 67-94, Latin American Studies Program, Cornell University, Ithaca.

1986 The Topará tradition: An overview, en: D.H. Sandweiss y D. P. Kvietok (eds.), Perspectives on Andean prehistory and protohistory, 35-46, Latin American Studies Program, Cornell University, Ithaca.

Recepción: 4/VI/2018

Aceptación: 17/VII/2018 